\title{
Kolloid-Zeitschrift
}

Zeitschrift für wissenschaftliche und technische Kolloidchemie

(früher „Zeitschrift far Chemie und Industrie der Kolloide")

Organ für das Gesamtgebiet der reinen und angewandten Kolloidchemie

Herausgegeben von

Prof. Dr. Wolfgang Ostwald in Leipzig, Brandvorwerkstrabe 77

Erscheint monatlich Imal Verlag yon THEODOR STEINKOPFF Dresden und Leipzig

Prels für den Band M. 18. -

\section{Untersuchungen über Bodenausblühungen.}

Von H. Puchner (Weihenstephan).

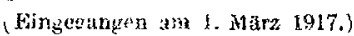

Unter Ausblühungen, Auswitterungen, Effloreszenzen versteht man Anflüge von meist weißer, manchmal aber auch anderer Farbe auf den Flächen verschiedener Körper bei ihrer Austrocknung. So entsteht an Mörtei und Mauern der als "Mauerfrab" bezeichnete Anflug ${ }^{1}$ ), der nach $P$. Rohland ${ }^{2}$ ) neben den weiken Sulfaten von $\mathrm{Na}, \mathrm{K}, \mathrm{Mg}, \mathrm{Ca}$, sowie $\mathrm{Na} \mathrm{Cl}$ und Natriumkarbonat auch gelblichgrüne vanadin- und molybdänsaure Salze enthalten kann. Auf Zementmörtel kommen nach Rohland Auswitterungen von Alkalisulfaten vor. Effloreszenzen von Karbonaten findet man an Zementbottichen in Bierbrauereien, und zwar rühren sie von der Soda her, die dem Zement zugesetzt wird, um dessen Hydratationsgeschwindigkeit zu beschleunigen. Kuprisuifat, zu Stuckgips gemengt, wittert quantitativ aus ${ }^{3}$ ). Auf getrocknetem süßhen Obst setzt sich Traubenzucker an. Und an der Oberfläche mancher Böden stoßen wir auf Anflüge von sehr verschiedener Ausbildung.

Was nun im besonderen diese Ausblähungen a u f Böden betrifft, so hat man ihnen lange Zeit wenig Beachtung geschenkt. Wie allen Effloreszenzen ist auch jenen der Böden die Ursache gemeinsam, nämlich die Verdunstung von Lösungen, welche das poröse Material durchdringen. Unterstützt wird der Vorgang wohl auch oft durch die starke

i) J. v. Lie big, Chemische Briefe.

2) P. Rohland, Die eigentliche Ursache der Auswitterungen an Steinen und Morteln (Koll.-Zeitschrift 8, 48, 1911). - Der holloide und kristalloide Zustand der Materie (Stuttgart 1910), 17.

3) Ebenda.
Volumverminderung, welche viele Böden beim Austrocknen erleiden. Bisher hat man fast stets nur die Lösungen von Stoffen im $\mathrm{k} \times \mathrm{i}$ stalloiden Zustand in Betracht gezogen, der Einflub kolloider Beimengungen ist bis jetzt werng beachtet worden.

Die Verdunstung erfolgt an der Oberfiâche. Hierdurch erhöht sich die Konzentration der Lösung unter gleichzeitiger Nachsaugung neter salzhaltiger Bodenflüssigkeit immer mehr, bis Kristallisationslonzentration erreicht ist und Kristallisation beginnt ${ }^{4}$ ). Je leichter löslich das Salz ist, desto mehr beschränkt sich die Ausbluthung nur auf die Bodenoberfiache. Ist aber ein schwer lösliches Salz in der Bodenflüssigkeit enthalten, so wird die Kristallisationskonzentration nicht erst an der Oberfläche, sondern bereits in einer tieferen Bodenschichte erreicht. Man stöbt dann berejts im Bodeninneren au? Ausscheidungen.

Schon hierdurch ist angedeutet, dab selbst die Ausblühungen kristalloider Stoffe verschiedener Natur sein können. Früher begniăgte man sich allerdings in der Regel damit, die Bodeneffloreszenzen, ohne sie näher zu wntersuchen, als $S$ alpeter (,Saliter $\left.{ }^{a}\right)$ anzusprechen. Es war dies nahcliegend, weil in heiben, regenarmen Gegenden tatsächlich in groBem Umfang salpeterhaltige Auswitterungen vorkommen. Größte Wichtigkeit und Berühmtheit kommit dem südamerikanischen Chilesalpeter 20 , der abe: infolge seiner kompakten Ausbildung nicht nehr

4) E. Ramann, Bodendurate (Berlin 1911), 79 .

5) Vgl. H. Grunci, Z, Zir heminis der Salpeterböden (Dentsche Landwir s.haftiche Presse, Berhn 1909$, Ni. 46$)$. 
als Eifloreszenz bezeichnet werden kann. Ohne auf die verschiedenartigen Hypothesen ${ }^{5}$ ) eingehen zu wollen, welche die Entstehung des Chilesalpeters zu erklären versuchen, sei hier nur darauf hingewiesen, daB das Auftreten salpeterhaltiger Auswitterung sehr naheliegend in Zusammenhang mit Nitrifikation des Sticksioffs organischer Substanzen durch die Tätigkeit von Bakterien unter günstigen klimatischen Verhältuissen zu bringen ist. Echte Salpetererden finden sich, abgesehen von noch vielen anderen außereuropäischen Lagen, auch in Ungarn, jedoch nur von beschränktem Umfang im oberen Theibgebiet nahe von Ansiedelungen und Weideplätzen, auf denen sich früher grobe Dungmassen anhäuften, deren Stickstoffgehalt durch die Tätigkeit nitrifizierender. Bakterien bei Kalkgegenwart in Salpeter übergeführt wurde.

Aber nicht im entferntesten alle Salzauswitterungen auf Böden sind als Salpeterbildungen anzusprechen. So weist H. Gruner gerade in Hinblick auf die in Ungarn vorkommenden "Salpeterböden", bei sandiger Beschaffenheit "Szekböden", bei toniger Artung "Szikböden" genannt, darauf hin, daß sie, abgesehen von den bereits erwähnten Ausnahmen, keinen Salpeter, sondern Soda, bisweilen auch Natriumsulf at enthalten. Es sind sog. Alkaliböden, wie wir sie eingehend aus den Untersuchungen von E. W. Hilgard ${ }^{6}$ ) als namentlich im Gebiet des ariden Westens von Nordame. rik a vorkommend kennen gelernt haben. Die dort und auch anderwärts mit weiBer Farbe ausblübenden Salzkrusten enthalten überwiegend Natriumsulfat neben etwas Chlornatrium. Und die damit bedeckten Ländereien werden als "weiBe Alkalibö den " bezeichnet, während den mit mißfarbig braunen, dunklen Ausbiühungen ausgestatteten, schwarzen Alkaliböden" ihre besondere Beschaffenheit an der Oberfläche durch den Gehalt der Auswitterung an Soda verliekten wird, welche infolge ihrer alkalischen Reaktion die humosen Stoffe des Bodens zum Teil zu einer kaffeebraunen, die Salzkruste durchziehenden Lösung umwandelt. Diese Soda bildet sich bei Gegenwart von kohlensäurereicher Grundluft und Kalk aus dem sclion vorhandenen Natriumsulfat des Bodens; dieses aber verdanki seine Entsiehung der Unsetzung von Gips im Boden mit bei der Zersetzung von Mineralien auftretenden

6) E.W. Hilgard, Solls, Their Formation, Properties, Composition and Relations to Climate and Plant Growth in the Humid and Arid Regions (New York 1906).
Natriumsalzen ohne reichliche Mitwirkung von Kohlensäure. Auch die in Uruguay und Argentinien als "Salpeterblüte" bezeichnete Auswitterung ${ }^{7}$ ) besteht aus $\mathrm{Na}_{2} \mathrm{SO}_{4}, \mathrm{NaCl}, \mathrm{Na}_{2} \mathrm{CO}_{3}$, $\mathrm{MgSO}_{4}, \mathrm{CaSO}_{4}$. Ebenso kann außer den bisher betrachteten Salzen nach P. Kossowits $\mathrm{ch}^{8}$ ) auch $\mathrm{Natriumsilikat}$ in den Alkaliböden vorkommen.

Das regenarme Klima, das an den bisher bezeichneten Oertlichkeiten des Auftretens von Bodenausblühungen gegeben ist, begünsligt die Auswitterung selbstredend ganz auBerordentlich. Aber auch unter Himmelsstrichen mit größerer Regenhäufigkeit können sich Verhältnisse ausbilden, welche das Zustandekommen von Bodenausblühungen begünstigen. So erwähnt $\mathrm{Gruner}$ Böden in der Niederung östlich von Gr.Schwechten in der Altmark (am Eichstädter Weg), die im trockenen Zustand reichlich kleine Klümpchen von faserigen Salzmassen enthalten. Diese bestehen aus Gips, der aus einer Schichte des Untergrundes stammt und gelöst auf kapillarem Wege in die Ackerkrume gelangt. Auch Verf. stieß im Lettenboden des Buntsandsteins auf nadelartige Salzausblühungen. Der Ort des Vorkommens, der sog. Pechlergraben bei $\mathrm{B}$ ad Reichenhall, unmittelbar neben der Bahnlinie und der Landstraße nach Berchtesgaden, ist durch das Auftreten mächtiger Gipsadern gekennzeichnet, wodurch die Vermutung nahegelegt wird, daß es sich auch bei diesen Ausblühungen um Gipskristalle handle. Diese Schlubfolgerung erwies sich aber als falsch. Die chemische Untersuchung ergab nur Spuren von Kalziumoxyd, vielmehr bestanden die ausgewitterten Nadeln fast ausschließlich aus Magnesiumsulfat. Die hier vor sich gegangene Umsetzung ist dadurch aufgeklärt, daB im Untergrund Dolomitgestein ansteht und solches auch durch Niederbrüche von oben dem Boden beigemengt ist. F. v. Kobel1 ${ }^{9}$ ) weist die gleiche Ausblühung für verschiedene Stellen in der Umgebung von Berchtesgaden nach, ebenso W. v. Gü $m b$ e ${ }^{10}$ ) für das fränkischè Werratal. Hier mag auch darauf hingewiesen

7) J. Schröder, Revista đel Instituto N. de Agronomia 12, 15-18 (1913).

8) P. Kossowitsch, Die Alkalibüden, das Verhalten der Pfianzen ihnen gegeniber und die Methoden zur Untersuchung der Alkaliböden. (Russ. Journ. f. exp. Landwirtsch. 4, 43, 1903, mit Wiedergabe des Inhalts der Originalarbeiten in deutscher Sprache.) 127.

9) F. v. Kobell, Die Mineralogie (Leipzig 1878),

10) W. v. Guimbel, Geologie von Bayern $\mathbf{3}$ (Kassei 1888, 718 . 
werden, dab im ganzen Verwendungsgebiet des Dolomites der Alpen als Baustoff für Bruchsteinmauerwerk an Gebäuden in Südbayern ein

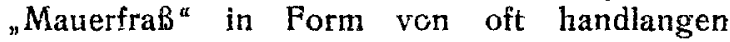
Rasenbüscheln weißer, dünner Kristallnadeln angetroffen wird. Verf. hatte Gelegenheit, diese Ausblühungen aus verschiedenen Bauten und zwar meist feuchten Kellerräumen entstammend, zu untersuchen. Die Analyse ergab fast reines Magnesiumsulfat. Die Bildung von Bittersalz ist hier auf die gleiche Umsetzung wie im Letten des Buntsandsteins zurückzuführen, denn das Hauptdolomit, namentlich in Südostbayern, ist oft sehr gipsreich.

Sehr häufig kommen Auswitterungen auf Mo o r böden vor. Am auffallendsten treten uns diese Gebilde in den sog. Mineralmooren entgegen. Der Name rührt daher, daB sich in diesen Mooren die Metallverbindungen, welche fast jeder Torfmasse in geringen Mengen beigemischt sind, so stark angehäuft haben. daf der vegetabilische Charakter der Torffaser fast zurücktritt und der Gesamteindruck dem einer Erz- und Salzablagerung nahe kommt. Als Ausgangspunkt derartiger Bildungen haben wir eisenreiches, kohlensäurehaltiges Wasser zu betrachten, welches in das Moor eintritt und hier durch Gegenwart der faulenden, schwefelhaltigen Pflanzensubstanz zur Bildung yon $S \mathrm{ch}$ wefele is en Veranlassung gibt. Diese Verbinđung imprägniert allmählich den gesamten Torf, auperdem geht sie aber sehr leicht an solchen Steilen, wo sie besonders der Luft ausgesetzt ist, in Eisenvitriol über, der bei trockener Witterung in Kristallen oder krustenförmiggen Ueberzügen ausblüht. Dies ist der Fall in einigen böhmischen Mooren bei Franzensbad "in der Sos", welche bekanntlich hierdurch zu medizinischen Zwecken geeignet sind und schon vor langer Zeit nutzbringend verwertet wurden. Auch auf andere Mineralmoore wurde schon wiederholt hingewiesen, so auf jenes bei Gunzendorf an der Linie Nürnberg-Eger, welches in heißen Sommern $2-3 \mathrm{~cm}$ mächtig von auswachsenden Kristallkrusten "wie mit Schnee überdeckt" sich darstellt ${ }^{11}$ ). Nach der schon weit zurückliegenden Veröffentlichung von Analysenbefunden des Bayerischen Gewerbemuseums in Nürnberg handelt es sich auch hier um Eisenvitriol; auferdem weist der ausgelaugte Moorrückstand einen nicht unbeträchtlichen $\mathrm{Nickelgehalt}$ auf. Von weiteren Salzen, die in Mooren aus-

11) H. Puchner, Mineralmoore (Münchn. Neueste Nachr. 23. Nov. 1893). wittern können, sind $\mathrm{Gips}$ und $\mathrm{Alaun}$ zu nennen, erklärlich durch die Gegenwart von Eisenvitriol neben kalkig - tonigen Bestandteilen.

Die Möglichkeit von Ausbiühungen auf Moorböden ist verständlich, wenn man bedenkt, welch große Mengen von Feuchtigkeit die Torfmasse aufzuspeichern vermag und wie. stark die Verdunstung aus dem porösen Moor in trockener Jahreszeit unter dem Einflub der starken Erwärmung des dunkel gefärbten Bodens ist.

Bis zur völligen Austrocknung geht die Verdunstung aus den nach allen Seiten freien ausgestochenen Torf $z$ i egeln, welche bei der Verwertung der Moore zu Heizzwecken anfallen. Beschläge auf getrockneten Torfbrocken können daher nicht überraschen. Aber über die Natur dieser Ausblühungen herrschen zum Teil ganz falsche Anschauungen. So wird auch in diesem Falle oft vorschnell von "Salpeterböden" gesprochen, ohne daß die tatsächlichen Verhältnisse die geringste Berechtigung hierzu geben. H. Gruner ${ }^{12}$ ) bespricht wiederum auch einige solche Böden aus Westpreußen, beispielsweise sandigen Humus von Rittergut $L$ anden bei Briesen und Torfziegel von $\mathrm{S} c h$ önsee. Obwohl ersterer in dortiger Gegend $z u$ den typischen Salpeterböden gerechnet wird und auf den zuletzt genannten Torfstücken starke weiße Beschläge auftreten, konnte doch in keinem Falle Stickstoff in Form von Salpetersäure nachgewiesen werden. Es lagen vielmehr, wie sich Gruner ausdrückt, niedere pflanzliche Gebilde vor. Auch Verf. entdeckte auf Torfstücken verschiedener Moore, wahrscheinlich verursacht durch nicht ganz trockene Lagerung, stürker oder schwächer ausgebreitete Pilzmyzelien von weiBer Farbe, mehr oder weniger seideglänzend und von dünnhäutiger Ausbildung. Regelmäbig jährlich wiederkehrender mehlartiger Duftbehang konnte ferner vom Verf. auf Fasertorf des bayerischen Pullinger-Moores bei Freising festgestellt werden, das einen Ausläufer des Dachauermoores bildet. Der Beschlag war in Wasser und Säuren unlöslich, kieselsäurehaltig und ließ ebenfalls niedere Pflanzengebilde vermuten, unterschied sich also gründlich von oberflächlichen Ueberzügen, die von der Verbłunstung von Lösungen herrühren, die Kalziumbiharbonat enthalten.

Wir haben aber noch weitere effloreszenz. artige Bildungen an Torfstücken $z u$ verzeichnen.

12) H. Gruner, Zur Kenntnis der Salpeterboden (Deutsch. Landwirtscinaft. Presse Berlin 1909, Nr. 46). 
welche sich von eigentiichen Salzeffloreszenzen wesentlich unterscheiden. Letztere entstehen durch die Verdunstung von Lösungen mit Stoffen im kristalloiden Zustand überhaupt. Wir wissen jedoch, daßs gerade im Torf sehi leicht durch die Gegenwart absorptiv schwach gesättigter Humusstoffe auch kolloide Lösungen entstehen und oft lange (Schutzkolloide) trotz reichlicher Gegenwart von Elektrolyten erhalten bleiben. Es kann bald die eine, bald die andere Lösung überwiegen. Die Stoffe der kristalloiden Lösungen werden nach P. Rohlan $d^{13}$ ) quantitativ an der Oberfläche der Torfstücke erscheinen, während die Stoffe der kolloiden Lösungen nicht auswittern können, sondern im Innern der Torfmasse verbleiben. Dabei ist noch $z u$ bedenken, daß nach der Kristallinitätstheorie von P. P. v. We i ma $\mathbf{n}^{14}$ ) alle möglichen Uebergänge zwischen kristalloid und kolloid denkbar sind, also auch die Aus. witterungsfähigkeit in allen möglichen Graden gegeben sein kann. Effloreszenzen und ihnen verwandte Bildungen können demnach nicht

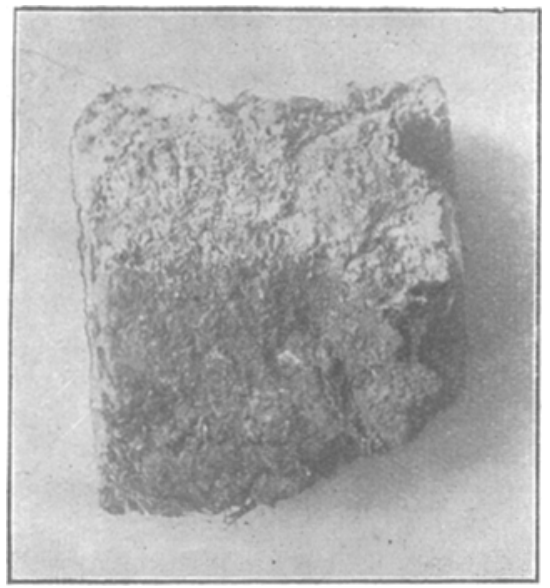

Abb. 1

Niederungstorf mit kalkigen Ueberzug.

(Die weiße Kalkkruste laßBt nur an einzelnen Stellen die darunter liegende dunkle Torisubstanz erkennen.)

19) P. Rohland, Die eigentliche Ursache der Ariswitterungen an Steinen umd Morteln (Koll.-Zeitschitit 8, 48. 1911).

14) P. P. v. Weim a rn, Koll.-Zeitschr. 2, 81 (1907) und zahlreiche Arbeiten in den folgenden Barden. nur an der Oberfläche, sondern in allen möglichen Schichten dazu geeigneter Boden auftreten, wie dies E. Raman ${ }^{15}$ ) auch schon für schwerlösliche Salze betont.

Die genauere Betrachtung vieler Torfziegel

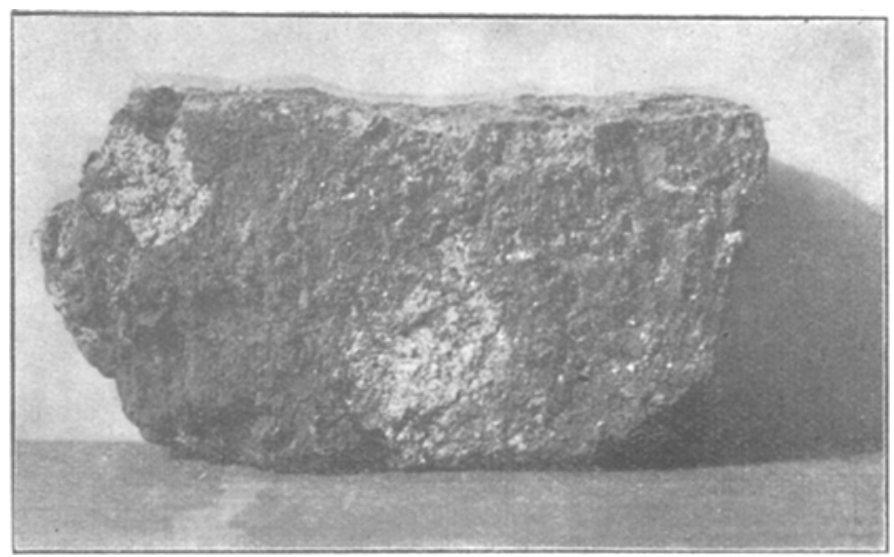

Abb. 2

Niedermingstorf mit eingebetteten kalkhaltigen Könchen und Krusten auf den Bruchflachen.

bestätigt eine solche Auffassung. So finden wir beispielsweise hierher gehörige Bildungen $\mathrm{kalkiger}$ Natur auf Torfbrocken süddeutscher und mitteldeutscher Niederungsmoore nicht nur in Porm von mehlartigen, weifen Ueberzügen an der Oberfläche (Abb. 1), sondern auch durch die ganze Masse verteilt bald als winzige, bald auch größere weiße Körnchen, dann als Krüstchen ilesterweise eingebettet (Abb. 2).

Die kalkigen Abscheidungen in der Torfmasse können nicht befremden, wenn man bedenkt, daß viele dieser Niederungsmoore auf einem kalkreichen Mergel, dem sog. "Alm " (in Bayern ), „Elm" (in Schwaben) aufruhen, einer Bildung, welche sich aus dem kalkreichen Grundwasser bei genügender Konzentration unter bestimmten, noch nicht ganz klar gestellten Verhältnissen niederschlägt. $\mathrm{Da}$ dies kalkreiche Wasser aber auch nach oben in die Torfmasse eindringt, kann die Entstehung von Auswitte. rungen an der Oberfläche von Torfziegeln leicht erklärt werden. Dieser äußere Beschlag löst sich unter Brausen fast vollkommen in $\mathrm{HCl}$. Etwas stärker verunreinigt scheinen die Kornchen und nesterweise eingelagerten Krusten zu sein, welche neben $\mathrm{CaCO}_{3}$ (90 Proz. und daräber) auch Magnesia, Eisen, Alkalien und namentlich organische Stoffe enthalten. Aus

15) E. Ramann, Bodenkunde (Berlin 19i1), 46. 
eigenen Versuchen des Ver.$^{16}{ }^{16}$, unterstützt durch die Ergebnisse anderweitiger Untersuchungen, kann die Anschauung abgeleitet werden, dab ein gewisser Gehalt an Kalziumoxydhydrat und auch an Alkalihydrat im "Alm" und in den weiBen Ausscheidungen des Torfs der Niederungsmoore zu vermuten ist. Die Ursache dieser möglichen Beimengung darf eben in den kolloiden adsorptiv schwach gesättigten, früher als "sauer" bezeichneten Humusstoffen erblickt werden, welche $\mathrm{OH}$-Gruppen abzuspalten vermögen. Läßt man nämlich die erwähnten kalkreichen Absonderungen mit Wasser aufgeschlämmt stehen, so setzt sich am Rande der Flüssigkeit unter Abnahme ihres Gehaltes an $\mathrm{CaO}$ und $\mathrm{Na}_{\mathrm{z}} \mathrm{O}$ eine schwache, alkalisch reagierende, auch nach langem Verweilen an der Luft mit $\mathrm{HCl}$ nicht brausende Kruste an. Damit hängt wohl auch die in Almgegenden landläufige Anschauung zusammen, daß "Alm" pflanzengiftig wirkt. Da im Moorwasser immer wieder neuerdings schwach gesättigte Humusverbindungen gebildet werden, bleiben die, wenn auch nur in geringen Mengen, schon entstandenen $\mathrm{OH}$-Verbindungen als solche erhalten und vor dern Uebergang in Karbonate bewahrt.

Aber auch noch andere Ausscheidungen im Torf scheinen auf Vorgänge kolloider Art zurückführbar zu sein. Schon v. Gü $\mathrm{mbe}{ }^{17}$ ) lenkte die Aufmerksamkeit auf das mit Vivianit bezeichnete wasserhaltige basische $E$ is en oxydphosphat ${ }^{18}$ ), das aber in Torf ursprünglich noch nicht mit der diesem Mineral eigenen blauen Farbe entsteht, sondern zunächst als weißes phosphorsaures Eisenoxydulhydrat (Cörulescit) gebildet wird. Sehr häufig findet man auch an Torfziegeln graue, braune, rote Belage, oft bis $5 \mathrm{~mm}$ und darüber mächtig. Es sind dies die an den benachbarten Torfmengen haftengebliebenen $B r u c h f l a ̈ c h e n$ von $G$ ängen und Adern (Abb. 3) im Moor, welche wahrscheinlich mit eisenhaltigen, kalk- und tonerdehaltigen kolloiden bumosen Lösungen angefüllt waren, deren Stoffe nach der Verdunstung des Wassers zurückblieben

16) H. Puchner, Neue Untersuchungen über das Schweben und die Ausflockung feinster Teilchen in wasserigen Aufschwennmungen (Die landwirtschaftlichen Versuchsstationen 1909, 263, 264. 267).

17) v. G a m bel, Grundzuge der Geologie (Cassel 1888), 211.

18) Unter den durch F. Cornu (Spezialheft der Koli.-Zeitschr. 4, 275, 1909) festgestellten Gelen des Mineralreichs befinden sich auch wasserhaltige Phosphate. oder auch schon vorher bei einer gewissen Konzentration ausgeflockt wurden. Die Untersuchung einer derartigen ockerartigen Ausscheidung aus dem bayerischen Erdingermoor ergab Unlöslichkeit in Wasser, Alkohol, Aether, Schwefelsäure, Salpetersäure, Essigsäure, Ammoniak, kaustischen und kohlensauren Alkalien, während das grell gelbrote Pulver leicht in verdünnter $\mathrm{HCl}$ löslich war. Die Analyse der intensiv gelb gefärbien Flässigkeit wies neben

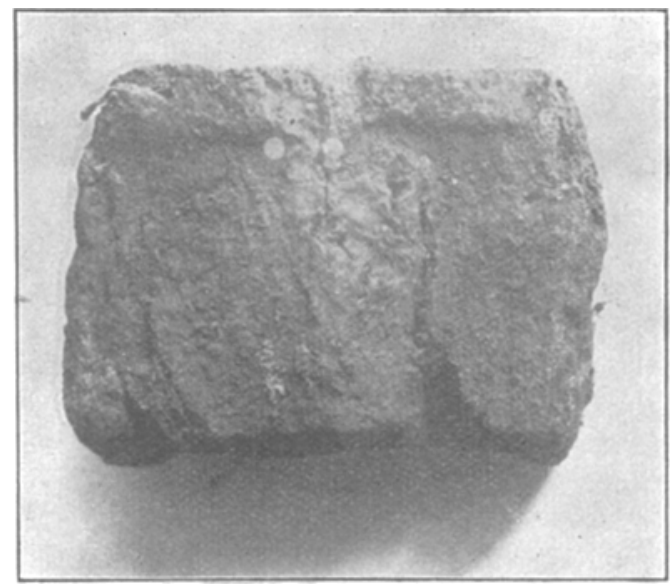

Abb. 3

Eisenhaltige Ader im Torf des Erdingermoores.

Eisenoxyd, etwas Kalk und Magnesia, sehr reichlich organische Substanz nach. Es lag ein eisenhaltiger organischer Farbstoff vor. Auch die Mitwirkung von Bakterien wurde bekanntlich bei der Bildung derartiger eisenreicher $A b$ sätze im Boden schon "nachgewiesen.

Wenn durch die bisherige Aufzählung auch schon bestimmte Typen von Effloreszenzen aut Böden herausgegriffen werden konnten, so kann dies doch nur als ein winziger Bruchteil von dem aufgefabt werden, was auf diesem Gebiete noch der Aufklärung harrt. So ist ein stark hervortretendes Merkmal der Bodenausblüh ungen dadurch gekennzeichnet, dab sie nur selten in ihrem äuBeren Bild jenen Formen entsprechen, welche bei dem der ermittelten $\mathrm{Zu}$ sammensetzung nach vorliegenden Salz auftreten, wenn es als Mineral vorkommt. Die Ursachen hierfür können nur in entsprechenden Einflüssen des Bodens gesucht werden, aus welchen die Auswitrerung stattfindet. Verf. hat es deshalb unternommen, bestimmte Bodentypen mit bestimmten Salzen $z u$ versetzen und das sich jeweils ergebende Bild der Ausblüh ungen näher zu studieren. Zunächst wurde 
ein Salz mit elektropositivem. Ion verwendet, nämlich chemisch reines $\mathrm{NaCl}$. Von den $\mathrm{Er}$ gebnissen dieser Versuche soll nachstehend berichtet werden. Sie haben den Verf. mehrere Jahre hindurch mit geringen Unterbrechungen beschältigt.

Die Verschiedenartigkeit der Ausblühungen aus verschiedenen Bodenarten bei gleichem Salzgehalt derselben.

Eine Reihe von Boden, welche unten näher bezeichnet sind, wurde in kleinen Porzellanschalen mit einer sorgfältigst hergestellten Lösung chemisch reinen, geglühten Chlornatriums in solcher Menge versetzt, dab der Salzge. halt des Bodens genau 3 Gew.-Proz. betrug. Dann kamen die in die Schalen gefüllten, dicht gelagerten Böden, welche sich im Zustand der "Einzelkornstruktur" (nach Wollny) befanden, an einem nur mäBig warmen Ort zur Aufstellung und wurden dem Vorgang der Verdunstung überlassen. Zum Zwecke photographischer Aufnahmen kamen die gleichen Versuche auch in flachen Glaswannen von $3 \mathrm{~cm}$ Höhe und $12,5 \times 6,5 \mathrm{~cm}$ Grundfläche, die in der Folge wiederholt abgebildet sind, zur Ausführung.

Der Versuch begann mit folgenden Böden am 7. November 1910 und ergab an den weiterhin verzeichneten Terminen die jeweils angegebenen Grade und Eigentümlichkeiten der eingetretenen Ausblühungserscheinungen.

Tabelle l.

\begin{tabular}{|c|c|c|c|}
\hline & 17. November & 1. Dezember & 22. Dezember \\
\hline Quarzsand von Nurnberg & $\begin{array}{l}\text { Erscheinen von mehr oder } \\
\text { weniger zusammenhängen- } \\
\text { den farblosen Krüstchen }\end{array}$ & $\begin{array}{c}\text { Ausbildung grober Salz- } \\
\text { klümpchen, welche Quarz- } \\
\text { körner einschlieBen }\end{array}$ & $\begin{array}{l}\text { Vorhandensein einer zusam- } \\
\text { menhangenden, lückenlosen, } \\
\text { tropfsteinartigen Salzkruste } \\
\text { von mattweißer Farbe auf } \\
\text { dem trockenen Boden }\end{array}$ \\
\hline $\begin{array}{l}\text { Quarzsand von Unterhausen } \\
\text { (Schwaben) }\end{array}$ & $\begin{array}{c}\text { Auftreten vereinzelter } \\
\text { farbloser, feinster } \\
\text { Kriställchen }\end{array}$ & $\begin{array}{l}\text { Ausbildung zahlreicher, } \\
\text { weit aifragender } \\
\text { Ktiställchen }\end{array}$ & $\begin{array}{l}\text { Vorhandensein einer sehr } \\
\text { starken, lückenlosen, moos- } \\
\text { polsterartigen und nadelfor- } \\
\text { migen, hohen Ausblïhung. } \\
\text { auf dem trockenen Boden }\end{array}$ \\
\hline $\begin{array}{l}\text { Niederungstorf von Hall- } \\
\text { bergmoos bel Freising }\end{array}$ & $\begin{array}{l}\text { Keine Spur } \\
\text { von Ausblühung }\end{array}$ & $\begin{array}{l}\text { Keine Spur } \\
\text { von Ausblühung }\end{array}$ & $\begin{array}{l}\text { Keine Spur von Ausblühung } \\
\text { auf dem trockeneu Boden }\end{array}$ \\
\hline $\begin{array}{l}\text { Hochmoortorf von Haspel- } \\
\text { moor bei München }\end{array}$ & $\begin{array}{l}\text { Keine Spur } \\
\text { von Ausblühung }\end{array}$ & $\begin{array}{l}\text { Keine Spur } \\
\text { von Ausblühung }\end{array}$ & $\begin{array}{l}\text { Keine Spur von Ausblühung } \\
\text { auf dem trockenen Boden }\end{array}$ \\
\hline $\begin{array}{c}\text { Sandiger Ton von Lauingen } \\
\text { (Schwaben) }\end{array}$ & $\begin{array}{l}\text { Keine Spur } \\
\text { yon Ausblahung }\end{array}$ & $\begin{array}{c}\text { Ausbildung einzelner } \\
\text { schwacher, baumartiger } \\
\text { Ausblihungen }\end{array}$ & $\begin{array}{l}\text { Vorhandensein einer starken, } \\
\text { aber nicht zusammenhängen- } \\
\text { den,baumartigenAusblühung } \\
\text { auf dem trockenen Boden }\end{array}$ \\
\hline Kâoiln von Akensberg & $\begin{array}{l}\text { Keine Spur } \\
\text { von Ausblühung }\end{array}$ & $\begin{array}{l}\text { Keine Spur } \\
\text { von Ausblibhung }\end{array}$ & $\begin{array}{l}\text { Schwach erhabene, weiße, } \\
\text { gerade noch sichtbare An- } \\
\text { sätze von Ausbiuhung auf } \\
\text { dem trockenen Boden }\end{array}$ \\
\hline Gelber Lehm von Freising & $\begin{array}{l}\text { Auftreten kleiner, kreis- } \\
\text { formiger, gelb gefärbter, } \\
\text { aber nur vereinzelt } \\
\text { stehender Ausbliihungen }\end{array}$ & $\begin{array}{c}\text { Ausbildung mehrerer } \\
\text { schwach erhabener, kleiner } \\
\text { Sternchen mit kreisförmigen } \\
\text { Umrissen }\end{array}$ & $\begin{array}{l}\text { Stärkeres Auftreten stern- } \\
\text { förmiger Krüstchen auf dem } \\
\text { trockenen Boden }\end{array}$ \\
\hline LoB von Günzburg & $\begin{array}{l}\text { Auftreten farbloser, } \\
\text { ziemlich zusammenhängen- } \\
\text { der, blättchenartiger Aus- } \\
\text { blühungen }\end{array}$ & $\begin{array}{c}\text { Ausbildung einzelner } \\
\text { regelmaBiger, vierseitiger } \\
\text { farbloser Kochsalzblättchen }\end{array}$ & $\begin{array}{l}\text { Vorhandensein einer zusam- } \\
\text { menhangenden Kruste von } \\
\text { vierseitigen Kochsalzblätt- } \\
\text { chen auf dem trockenen } \\
\text { Boden }\end{array}$ \\
\hline $\begin{array}{c}\text { Schwachtoniger Kalkboden } \\
\text { von Unterhausen } \\
\text { (Schwaben) }\end{array}$ & $\begin{array}{l}\text { Keine Spur } \\
\text { von Ausblühung }\end{array}$ & $\begin{array}{l}\text { Ausbildung einzelner } \\
\text { kleiner Sternchen von } \\
\text { federartiger Struktui }\end{array}$ & $\begin{array}{l}\text { Vorhandensein stärkerer, } \\
\text { sternförmiger Krustchen } \\
\text { auf dem trockenen Boden }\end{array}$ \\
\hline
\end{tabular}


Am 22. Dezember erfolgte neuerlicher $\mathrm{Zu}$ satz von Salzlösung zu den Böden in solchen Mengen, daB der Salzgehalt 6 Gew.-Proz. betrug. Bei der nun wieder folgenden Austrocknung der Böden verstärkten sich die bereits oben angegebenen Erscheinungen, ohne ein wesentlich verändertes, neues Bild zu ergeben. Nur bei Niederungstorf und Hochmoortorf war auch durch diese verstärkten Salzzusätze keine Ausblühung zu erzielen. Deshalb erfolgte bei diesen beiden Böden am 23. Januar 1911 abermals Zusatz von Kochsalzlösung, so daß die beiden Moorböden nun 12 Gew.- Proz. $\mathrm{NaCl}$ enthielten. Nach vollständiger Austrocknung am 22. Februar 1911 zeigte sich nun auch auf Niederungstorf von Hallbergmoos eine ganz schwache, farblose Kruste und auf Hochmoortorf von Haspelmoor das Auftreten ganz vereinzelter Salznädelchen. Beim Versetzen sämtlicher Erdarten mit Salzmengen nach volumprozentischem Verhältnis, wodurch bekanntlich der störende Einfluß des ungleichen spezifischen Gewichtes der Böden beim Vergleich der Versuchsergebnisse untereinander ausgeschaltet werden kann, ergab sich endlich ebenfalls kein wesentlich verändertes Bild.

Es ist also festgestellt, dab schon beim Ausblühen ein und desselben Salzes, das in gleichen Mengen in verschie. denen Böden enthalten ist, sich sehr groBe Abweichungen in bezug auf die Ausbildung der Effloreszenz ergeben und zwar nicht nur in bezug auf die Stärke derselben und die Schnelligkeit ihres Erscheinens, sondern auch in bezug auf die Form.

Eine Reihe von Fragen drängt sich bei näherem Eingehen auf diese Ergebnisse auf. Eine experimentelle Beantwortung hierauf kann aber nur durch umfangreiche Arbeiten von verschiedenen Gesichtspunkten aus erledigt werden. $V$ e $\mathrm{f}$. hat deshalb weiterhin den Versuch unternommen, einige Beiträge zur Klärung der vorliegenden Probleme zu gewinnen und möchte im folgenden auch hierüber berichten.

Selbstredend wird das Zustandekommen der Ausblühungen von den verschiedensten Faktoren beeinflubt. Als solche können wir neben der Verdunstung gleich von vorneherein nennen die Dampfspannung im feuchten Boden, die spezifische Zähigkeit der Salzlösung, deren Kapillaritätskonstante usw. $\mathrm{Da}$ aber bei allen Ausblühungsversuchen sämtliche Bedingungen unter sich durchaus gleich eingehalten wurden, mit Ausnahme eben der besonderen Eigenart des Bodens, so lassen die Versuche cinen SchluB darüber $\mathrm{zu}$, wie sich nach dieser Hinsicht die benützten Böden verhalten.

Der Bodenkandige wird nun an den vorstehend aufgeführten Ergebnissen bald als bemerkenswert herausfinden, daß unter den angewandten Versuchsbedingungen das Zustandekommen einer Ausblühung beim Moorboden auberordentlich erschwert, auch beim $\mathrm{Ka}$ olin sehr wenig bedeutend war, während in ungefähr aufsteigender Reihenfolge die Efflòreszenzbildung bei $L$ ehm, LöB und $S$ and begünstigt erschien. Es ist wohl kein Zufall, daß dieses Verhältnis übereinstimmende Beziehungen aufweist zu der absoluten Gröbe der Oberfläche der gesamten Teilchen der einzelnen Böden,

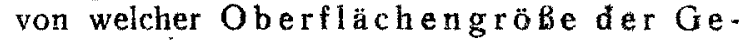
wichtseinheit des Bodens die adhäsive Festhaltung von Salzteilchen zwischen den Bodenteilchen, also ein Vorgang abhängig gedacht werden kann, der dem Erscheinen einer Salzkruste an der Bodenoberfläche entgegenzuwirken vermag. Diese Flächenentwicklung wird beispielsweise von E. A. Mits cherlich h $^{19}$ ) nach theoretischen Berechnungen wie folgt angegeben:

$\begin{array}{lc} & \text { Bodenoberiläche } \\ \text { von 1 } \mathrm{g} \text { Boden in qm } \\ \text { Tiefiand - Moorboden } & 747,9 \\ \text { Kaolin desgl. } & 766,5 \\ \text { Milder Lehmboden } & 219,2 \\ \text { Sandiger Lehmboden } & 121,8 \\ \text { Lehmiger Sandboden } & 84,9 \\ \text { Kohlensaurer Kalk } & 56,8 \\ \text { Feiner tertiärer Quarzsand } & 40,6 \\ \end{array}$

Und es ist ersichtlich, daß tatsächlich der unter den eingehaitenen Versuchsbedingungen am wenigsten zur Ausblühung neigende Tonf die gröbte, der Quarzsand, worauf Ausblühungen am leichtesten sich einstellten, die geringste Oberflächengröß̉e der Gewichtseinheit Boden aufweist.

Allerdings scheint die Schlubfolgerung dem Befunde von Rohland ${ }^{20}$ ) zu widersprechen, wonach Kuprisulfat, das zu Stuckgips gesetzt wurde, mehrere Stunden nach der Erhärtung quantitativ an der Gipsoberfläche erschien. Dabei handelte es sich aber um gegeneinander indifferente Körper und vollkommen kolloid-

19) E. A. Mitscherli ch, Bodenkunde für Landund Forstwirte (Berlin 1905), 71.

20) P. Rohland, Die eigentliche Ursache der Auswitterungen an Steinen und Mörteln (Koll.-Zeitschrift $8,48,1911$ ). 
freies Material, der Gips war durch den vorausgegangenen Brennprozefi jeder organischen Substanz beraubt worden, während in den hier vorliegenden Böden durchwegs humose Körper und Hydrogele von Aluminium, Eisen, Kieselsäure zugegen waren, welche zur Bildung von

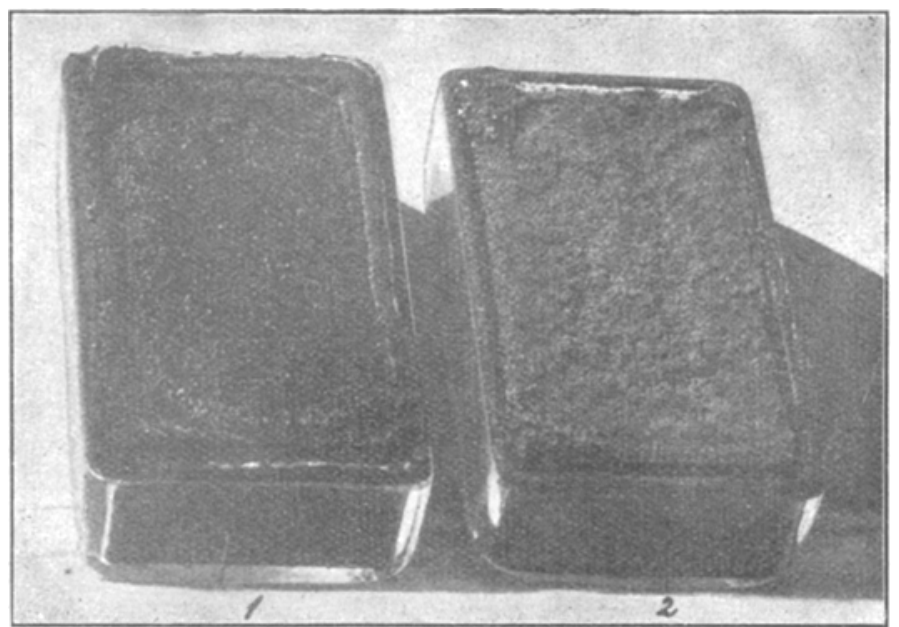

Abb. 4

Ausblühungen auf Niederungsmoor- (1) und auf Hochmoortorf (2) bei 12 Proz. $\mathrm{NaCl}$ - Gehalt.

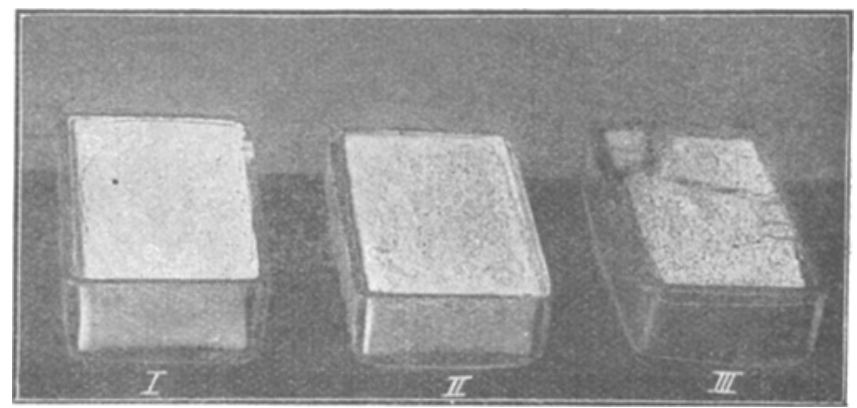

Abb. 5

Ausblühungen aus Böder bei 3 Gew.-Proz. $\mathrm{Na} \mathrm{Cl}$-Gehalt.
I. $\mathrm{CaCO}_{3}$,
II. $\mathrm{H}_{2} \mathrm{Si} \mathrm{O}_{\mathrm{g}}$.
III. Lehm.

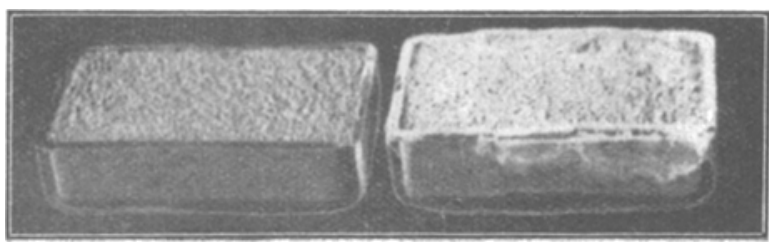

Abb. 6

Ausbluhung bei $3 \mathrm{Gew}_{n}$-Proz. $\mathrm{Na} \mathrm{Cl}$ - Gehalt auf Quarzsand (rechts)

Der gleiche Quarzsand ohne Salzgehalt, feucht eingefiilit, nach den Austrocknen (links). tend, dann beim Lehm (III in $\mathrm{Abb} .5$ ), noch stärker bei $L o ̈ B$, schwach tonigem

Solen geneigt sind und darin vor Ausflockung durch die Schutzwirkung der Humuskolloide bewahrt bleiben. Diese kolloiden Lösungen, welchen die Fähigkeit zur Auswitterung fehlt, werden aber im Gemenge mit kristalloiden Lösungen einen diesbezüglichen Einfluß auch auf diese ausüben und sie um so mehr im Boden zurückhalten können, je größer die Oberfläche sämtlicher Teilchen derselben ist, die sie zu überziehen haben, ganz abgesehen davon, daß $\mathrm{NaCl}$ an sich auch kolloiden Zustand anzunehmen vermag ${ }^{21}$ ).

Wir können es hiernach begreiflich finden, dah die beiden benützten Torfsorten mit ihrem Gehalt an Humuskolloiden und ihrer großen Bodenoberfläche noch bei 3 Proz. bzw. 6 Proz. Salzgehalt keine Spur von Ausblühung erkennen lieben und erst bei einem Salzgehalt von zwölf Proz. der Niederungstorf eine ganz schwache Kruste (1 in Abb. 4), das Hochmoor vereinzelte Nädelchen (2 in Abb. 4) an der Oberfläche aufwiesen ${ }^{22}$ ). Daß schließlich selbst unter solch ungünstigen Umständen durch die Verdunstung eine Effloreszenz zustande kommen kann, kann in Abb. 4 daran erkannt werden, dab Salzauswitterung noch am deutlichsten sich an den Rändern des Torfkuchens und besonders an dessen Ecken (2 in Abb. 4) einstellte, wohin die Salzlösung vorwiegend wanderte.

Schon etwas stärker machte sich die Ausblühung beim $\mathrm{Ka}$ olin mit seiner etwas geringeren Bodenoberfläche und mit durch Verf. deutlich feststellbarem Gehalt an wasserlös1) V. Pösch 1, Einführung in die Kolloidchemie (Dresden 1911), 28.

29) Das getinge spezifische Gewicht von Torf ist beim Zustandekommen dieser Beziehungen zwar auch beteiligt, läßt aber fur sich allein eine Erklärung nicht zu, denn auch beim gleichen volumprozentischen $\mathrm{NaCl}$-Gehalt waren die Äusblihungen sehr schwach.

23) Die wesentlichsten Kolloidsubstanzen des Tones sind Hydroxyde des Siliziums, Aluminiums, Eisens, vermutlich auch organische Substanzen (P. Rohland). 
Kalkboden, sowie endlich am stärksten beim ausgesprochenen $\mathrm{S}$ a ndboden (Abb. 6).

$\mathrm{Da}$ jedoch die stoffliche Beschaffenheit bei einzelnen Böden nicht ausgeprägt genug einseitig war, suchte Verf. auch noch mit einigen künstlich durch Fällung und Auswaschung gewonnenen Materialien Ergebnisse zu gewinnen, nämlich mit präzipitiertem Kieselsäurehy drat und Kalziumkarbonat. In Abb. 5 sind auch die damit erzielten Ausblühungen dargestellt und zwar unter I die Effloreszenz auf $\mathrm{CaC} \mathrm{O}_{3}$ und unter II jene auf Kieselsäurehydrat, während III die schon behandelte Ausblühung auf Lehm wiedergibt.

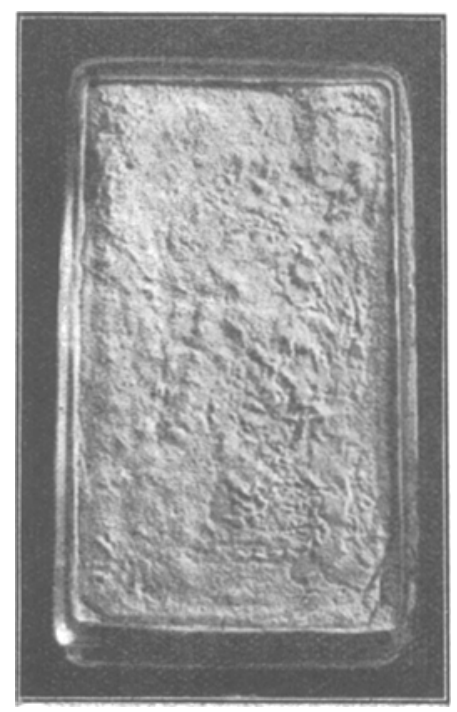

Abb. 7

Ausblühung auf Kieselsäur ehydrat mit 3 Gew.-Proz. $\mathrm{NaCl}$

Von der bräunlichen Lehmmasse, die in den Sprüngen des Bodenkuchens erkenntlich ist, hebt sich die mehlig krustige Ausblühung deutlich ab. Hingegen ist die Effloreszenz auf $\mathrm{CaCO}_{3}$ kaum erkenntlich, nicht nur deshalb, weil ihre Farbe vollkommen mit dem schneeweißen Kalkpulver übereinstimmt, sondern auch aus dem Grunde, weil sie nur als feines, dünnes Hăutchen ausgebildet ist. Es bleibt bemerkenswert, dab von einer quantitativen Ausblühung nach $\mathrm{Rohl}$ and auch auf dem reinen $\mathrm{CaCO}_{3}$ nicht im entferntesten die Rede war. Andererseits wieder erscheint das deutlich ausgeblühte Salz auf Kieselsäure in scharfer, unregelmäßiger Ornamentik, brokatstoffartig über die Oberfläche hingezogen, wie es im vergröBerten $\mathrm{MaB}$ stab Abb. 7 zeigt. Ein wesentlicher Unterschied zwischen dern Ausblühungsversuch auf diesem künstlich gewonnenen Kieselsäurematerial und jenem auf natürlichem Quarzsandboden muß aber gleich vorweg in der Weise betont werden, dab es sich hier um gefällte, wasserhaltige Kieselsäure handelt, deren Neigung zum kolloiden Zustand bekannt ist, während die Quarzsandböden der Natur doch überwiegend als aus Kieselsäureanhydrid bestehend anzunehmen sind.

Wenn auch durch solche Ergebnisse schon ein gewisser Hinweis vorliegt, in welcher Art verschiedene Böden zur Hervorbringung von Effloreszenzen geeignet sind, so ist die Ausbeute nach dieser Richtung doch immer noch nicht als besonders ergiebig bezeichenbar.

Der festgestellte Umstand aber, dab sandige Böden besonders zur Ausblühungsfähigkeit zu neigen scheinen, hat Verf. veranlabt, sich noch eingehender gerade mit diesen $z u$ beschäftigen. Es konnte nämlich auch schon im Verlaufe der bisher besprochenen Versuche erkannt werden, daB die Ausblühungen verschieden auftraten, je nachdem sie auf gröberem oder feinerem Sande entstanden. Deshalb wurden die in größerer Anzahl zur Verfügung stehenden Sandböden durch Sieben in verschieden feine Sortimente zerlegt. Und es kamen dann meist mit jedem der Sortimente für sich unter sonst gleichen Bedingungen Ausblühungsversuche zur Durchführung. Die abgesonderten Sandsortimente hatten die nachstehenden Bezeichnungen und Dimensionsgrenzen:

$$
\begin{aligned}
& \text { Sortiment Nr. I } \quad<0,25 \mathrm{~mm}
\end{aligned}
$$

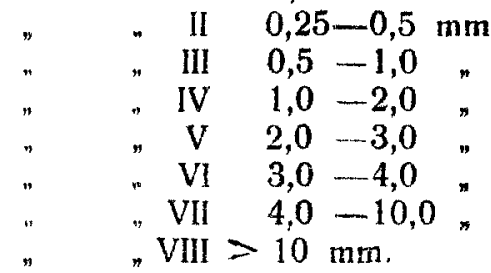

Die $\mathrm{NaCl}$-Lösungen wurden für jeden Versuch wieder neu hergestelit, um allenfallsige Entmischungen unscbädlich $z u$ machen. Der Bereitung der Lösung ging eine langandauernde Trocknung und ein Glühen des $\mathrm{NaCl}$ unter feinster Verreibung voraus. Ebenso wurden alle Rückstände der eingedampften Salzlösungen unter wiederholter Verreibung lang anhaltend getrocknet.

Als Zusatz wurden zu je $100 \mathrm{~g}$ sorgfältig getrockneten Sandes je $10 \mathrm{ccm}$ einer genau 30 prozentigen $\mathrm{Na} \mathrm{Cl}$ - Lôsung verwendet, so daß der in den flachen $3 \mathrm{~cm}$ hohen Glasgefäßen 
enthaltene Sand durchwegs 3 Gew.-Proz. Na Cl enthielt. Zur Kontrolle wurde jeweils die Salzmenge in $10 \mathrm{ccm}$ durch Eindampfen bestimmter Lösungsmengen und lange fortgesetzte Trocknung der verriebeneı Rückstände bei $105{ }^{\circ} \mathrm{C}$ bestimmt. Um die Lösung recht gleichmäBig in der Sandmasse zu verteilen, fand stets nach ihrem mit der Pipette erfolgenden gleichheitlichen und vorsichtigen Aufgiehen in einzelnen Tropfen-auf die. Bodenoberfläche eine Ueberbrausung mit destilliertem Wasser aus einer kleinen Spritzflasche statt. Dann wurden die Gefäße mit den dicht geschlämmten Böden im Zustand der "Einzelkornstruktur" an einem mäBig warmen Ort der Verdunstung überlassen. Die absichtlich gewählte geringe Höhe der GlasgefäBe war so bemessen, dab sie auch im gröbsten Sortiment von dessen schwacher kapillarer Steighöhe für die Lösung übertroffen wurde.

Außerdem fanden zu Analysenzwecken auch kleine Porzellanschalen Verwendung, worin je $100 \mathrm{~g}$ Boden, mit $10 \mathrm{ccm}$ der $\mathrm{NaCl}$-Lösung versetzt, der Austrocknung unterlagen. Zur Verwendung kamen:

1. Dolomitsand aus dem WeiBbachtal bei Bad Reichenhall (Oberbayern),

2. Schwach lehmiger, glimmerreicher Quarzsand aus dem "Quarzitwerk Massenhausen bei Freising (Oberbayern),

3. Etwas eisenschüssiger, humoser Quarzsand aus der Umgebung von Nürnberg,

4. Seesand von Pillau a. Ostsee.

\section{Ausblühungen a uf Dolomitsand.}

Der Versuch begann am 23. September 1913. Die einzelnen Sortimente verhielten sich wie folgt.

\begin{tabular}{|c|c|c|c|}
\hline & $\begin{array}{l}\text { Beginn der } \\
\text { Ausblühung }\end{array}$ & & $\begin{array}{l}\text { Beginn der } \\
\text { Ausblühung }\end{array}$ \\
\hline & 3. Oktober & V & 13. Oktober \\
\hline & 5. Oktober & VI & 16. Oktober \\
\hline & 8. Oktober & VII & 18. Oktober \\
\hline & 11. Oktober & VIII & 20. Oktober \\
\hline
\end{tabular}

Am 13. November waren die Ausblühungen auf allen Sortimenten des Dolomitsandes sichtlich vollendet. Das Bild, welches sie boten, und das in Abb. 8 dargestellt ist, wies folgende Verschiedenheiten auf. Es hatte sich entwickelt auf Sortiment:
Tabelle II.

\begin{tabular}{l}
\hline Stark emporgetriebene, zusammenhängende, \\
mattweiße, nach unten eben begrenzte und \\
sich wie Pappe vom Sand abhebende Platte \\
(vgl. Abb. $8,9,10$ ) von $0,3-0,5 \mathrm{~cm}$ Machtig- \\
keit. Die Platte besteht nicht nur aus Salz- \\
teilchen, sondern enthält auch massentuaft die \\
feinsten Sandteilchen eingeschlossen. Die \\
Oberfläche der Salzplatte weist durch den Ein- \\
schluß von Sandteilchen entstandene Salzkörn- \\
chen auf. Kein Uebergreifen der Ausblühung \\
auf die GefäBaußenwand.
\end{tabular}

Nicht emporgetriebene, mattweiße Salzdecke

II. mit eingeschlossenen Sandteilchen. Uebergreifen der Ausblühung auf die Gefaßaußenwand.

Eingesunkene, mattweiße Salzdecke, nur spärlich Sandteilchen einschließend. Stärkeres Uebergreifen der Ausblühung auf die GefäßauBenwand.

IV. Eingesunkene, unebene, mattweiße Salzdecke. Starkes Herabreichen der Ausblühung an der Gefäßaußenwand.

Unebene, mattweiße Salzdecke ohne jeglichen

V. Einschiuß von Sandteilchen. Weniger starkes Herabreichen der Ausblïhung an der Gefäßaußenwand.

VI Tropfsteinartig ausgebildete, mattweiße Salzkrtiste, weitere Abnahme des Herabsteigens der Atusbluhung an der Gefäßaußenwand.

VII Tropfsteinartig ausgebildete, mattweiße, etwas übérhöhte Salzkruste. Ganz schwaches Herabstelgen der Ausblithung an der Gefäßaußenwand.

Tropfsteinartig ausgebildete, stark iberhöhte VIII2) Salzkruste von mattweiBer Farbe. Kein Uebergreifen der Ausblühung auf die Gefäßaußenwand.

Vor allem verdient die Tatsache Hervorhebung, daß Ausblühungen überhaupt zustande kamen. Es darf dies deshalb betont werden, weil es sich hier um einen natürlichen Boden mit deutlichem Gehalt an Humuskolloiden handelt. Stellt man sich wässerige Auszüge des Bodens her, so weisen sie beharrich entweder opalisierende oder noch stärker getrübte Beschaffenheit auf (Schutzkolloid). Und dampft man die Auszüge ein, so zeigen sich die charakteristischen Eigenschaften von Hydrosolen, beispielsweise leimige Konsistenz, Abscheidung von Flocken, sehr starke Hygroskopizität des bei $105^{\circ}$ getrockneten Rückstandes, die starke Schwärzung des kolloiden Rückstandes beim Glühen in der Platinschale beweist aber den organischen Charakter des Kolloidkomplexes.

4) In Abb. 8 nicht mit aufgenommen. 
Die qualitative Untersuchung des weib gebrannten, alkalisch reagierenden und nicht mehr hygroskopischen Restes endlich ergibt reichlich $\mathrm{CaO}, \mathrm{MgO}, \mathrm{Fe}_{2} \mathrm{O}_{3}$, ferner $\mathrm{Al}_{2} \mathrm{O}_{3}, \mathrm{Mn}_{3} \mathrm{O}_{4}$ und Alkalien. Die Möglichkeit des Vorhandenseins humoser Kolloidkomplexe in diesem Boden erscheint zudem leicht verständlich, denn er bildet den an einem schattigen, nördlichen $\mathrm{Ge}$ birgshang gelegenen Untergrund einer üppigen Nadelholzvegetation mit teilweise mächtigen $\mathrm{Ab}$ lagerungen von Alpenhumus.

Es besteht deshalb Veranlassung, jenen in in der Agrikuitur-Kolloidchemie wiederholt schon ausgesprochenen Satz, daf die Humus. kolloide infolge ihres Adsorptions. vermögens das Ausblühen wasserlöslicher Bodensalze verhindern, genauer in der Weise auszusprechen, daB Aus blühungen nur solange unterbleiben, als der Salzgehalt eine gewisse obere Grenze, die für einzelne Böden und einzelne Salze noch genauer $\mathrm{zu}$ bestimmen ist, $\mathrm{n}$ ich $\mathrm{f}$ überschreitet. Nur unter Festhaltung dieser Beschränkung können wir uns auch Rechenschaft übet die Entstehung von Bodenausblühungen in allen übrigen, weiter oben angeführten Fällen geben. Eine Verhinderung der Ausblühung durch die Humuskolloide findet also nur dann statt, wenn jener sehr geringe Salzgehalt vorliegt, der den natürlichen Böden normalerweise eigen ist. Steigt hingegen der Salzgehalt bedeutend, so können aus naheliegenden Gründen die $\mathrm{Hum}$ uskolloide des Bodens die Ausblühung nicht mehr ganz unterdrücken. Sie üben aber, wie noch näher dargelegt werden soll, einen in den einzelnen Böden verschiedenen $E$ inf 1 u $B$ auf die Form dier Ausbluhung aus.

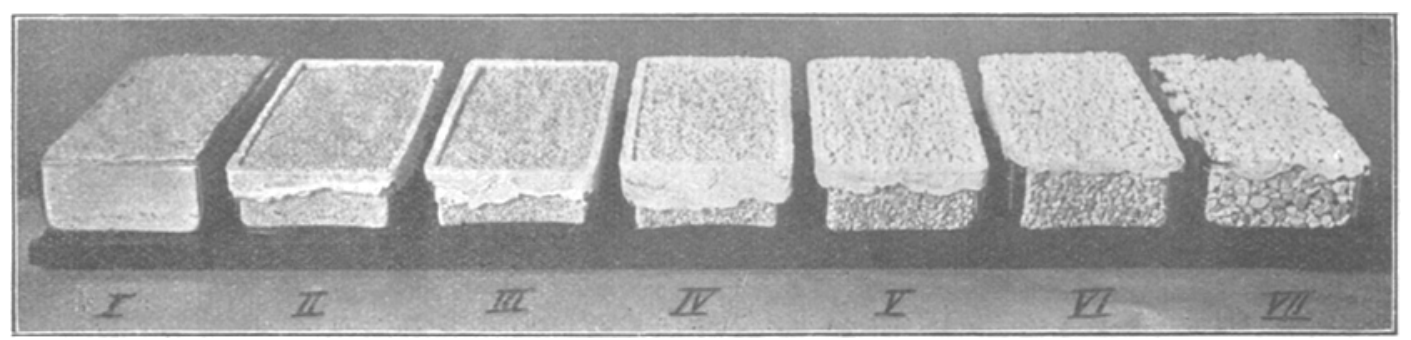

Abb. 8

Ausbluhungen auf Dolonitsand mit 3 Gew.-Proz. Na Cl. Sortimente: I-VII.

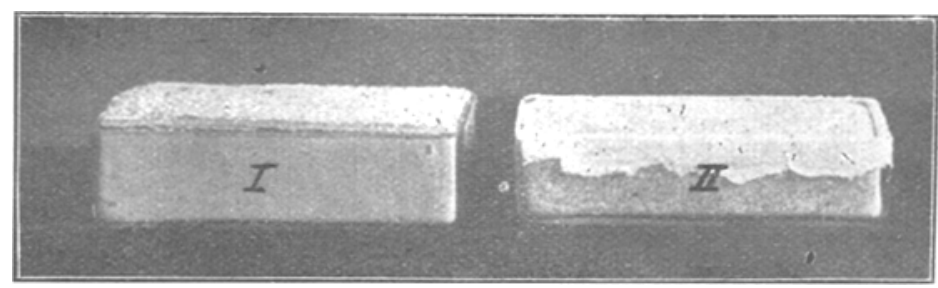

Abb. 9

Ansbluhungen auf Dolomitsand mit 3 Gew.-Proz. Na Cl. Sortiment I und II.

Wenn wir kurz das Typische aller Salzausblühungen von $\mathrm{NaCl}$ a uf Dolomitsand zusammenfassen wollen, so ist es die ungegliederte, zusammenhängende, derbe, plattenar. tige Ausbildung, die aber je nach dem die Unterlage bildenden Sandsortinent wieder ganz bestimmte, weitere Eigenheiten aufweist.

Auf dem feinsten Dolomits and 1 ist besonders bemerkenswert die über das ursprüngliche Niveau des feuchten Sandes zienlich weit emporgetriebene Lage der besonders starken Salzplatte, was schon aus Abb. 8

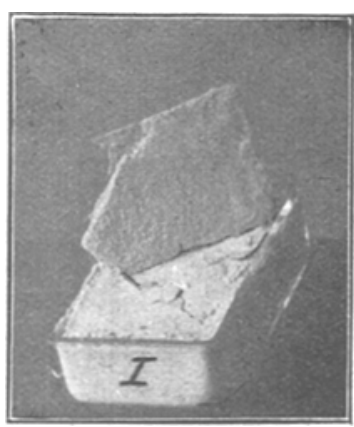

Abb. 10

Ausblühung auf Dolomitsand I mit $3 \mathrm{Gew}$.- Proz. $\mathrm{Na} \mathrm{Cl}$, als Platte abgehoben.

(unter 1), noch besser aus Abb. 9 ersichtlich ist. Diese Salzplatte läßt sich im gut zusammenhängenden Zustand von dem darunter befindlichen gewachsenen Sand abheben (Abb. 10) und weist nach u $\mathrm{n}$ te $\mathrm{n}$ (Abb. 10) eine ziemlich ebene Grenzfläche auf, während diese nach 
oben durch viele kleine Salzkörnchen und stellenweise ganz schwache Neigung derselben zur Nadelbildung gekennzeichnet ist. Ein Uebergreifen der Ausbiühung auf die GefäBauBenwand ist nicht einmal spurenweise vorhanden. Diese Befunde stimmen in der Hauptsache auch überein mit dem Ergebnis des Ausblühungsversuches auf gefälltem $\mathrm{CaCO}_{3}$ von chemischer Reinheit (Abb. 5, I). Nur war dort wohl infolge der noch viel höheren Feinheit der Bodenteilchen die Ausblühung mehr hautartig und mehlig und war auch nicht die geringste Neigung zur Nadelbildung erkenntlich, was auf das Fehlen solcher Beimengungen zurückzuführen sein dürfte, die in natürlichen Böden enthalten sind.

Die Salzdecken auf Dolomitsand II, III und IV lassen erkennen, wie in diesen Sortimenten bei der Ausblühung die emportreibenden Kräfte nicht mehr zu solcher Geltung gel angen konnten, daß eine Ueberschreitung des ursprünglichen Niveaus einzutreten vermochte. Die Ueberhöhung der Salzplatte ist schon bei Sortiment II gleich Null; bei Sortiment III und IV wird sie sogar negativ, d. h. die zunehmend dünner werdende, eingesunkene Salzdecke reicht mit ihrer Oberfläche immer weniger weit bis in das ursprüngliche, mit den oberen GefäBkanten abschneidende Niveau der Sandobetfläche herauf. Damit Hand in Hand geht in der gleichen Reihenfolge die Erscheinung, dab die Ausblühung immer weiter an der äuberen Gefäßwand herunterklettert.

Bei den ganz groben Sortimenten, nämlich Dolomitsand V, VI und VII, nimmt aber die Neigung der Ausblühung zum Uebertritt auf die äußere Glasfäche wieder in deutlichster Weise gleichmäßig $a b$, so daß bei dem Gefäß mit dem Sortiment VII (Abb. 8) fast keine Salzteile mebr außen haften. Im Zusammenhang damit zeigt in der gleichen Reihenfolge die Salzkruste an der Oberfläche eine $z$ unehmend unebene, tropfsteinartige Beschaffen heit.

Das sind die vorliegenden Tatsachen, die für sich selbst sprechen. Bei näherer Ueberlegung gelingt es aber auch, für diese Erscheinungen Erklärungsgründe zu finden, welche der Betonung der Wahrscheinlichkeit gewachsen sind. Es dürfte hier nämlich das Ergebnis der verwickelten Wechselwirkung verschie. de ner $K$ a pill a rvorgänge anzunehmen sein.

Die Ansammlung der im Boden vorhandenen Salzmengen an seiner Oberfläche zu einer Ausbluthung wird ohne Zweifel durch die Ver- dunstung hervorgerufen, die an der Grenzregion zwischen Boden und Luft stattfindet. Der durch die Verdunstung unterhaltene $\mathrm{ka}$. pillare Nachschub von Feuchtigkeit transportiert andauernd neue Salz. mengen nach oben, die schlieblich bei der Austrocknung des Bodens als festes Salz dort zurückbleiben. Dieser allgemeinen Abwickelung des Ausblühungsvorganges stehen aber im besonderen mancherlei Abstufungen gegenüber.

Die die Verdunstung steigernde Zunahme der Oberflächengröfe mit Abnahme der KorngröBe des Sandsortimentes würden es völlig erklärlich machen, dab die Ausblithung sich zuerst auf Dolomitsand I bemerkbar machte, und fortschreitend immer später, je gröber der Sand war. Allein der Unstand, dab bei anderen, weiter unten beschriebenen Sanden gerade das Gegenteil festzustellen war, weist darauf hin, dafi diese Erklärung nicht genügt. Es spielen hier jedenfalls noch mehrere Umstände mit, wie die geringe Höhe der Sandsäulen, die starke seitliche Erwärmung usw. Außerdem erfolgt der Transport von Wasser und Salzen in desto gröBere Höhen, aber auch um so langsamer, je feinkörniger der Sand ist, während im groben Sand die rasch erreichte maximale Steighöhe eine geringe ist. Infolgedessen hätte bei den hier vorliegenden niederen Bodensäulen die Auswitterung auch aus diesem Grunde zuerst auf den groben Sandsortimenten erwartet werden dürfen. Daß, wie gesagt, das Gegenteil zu beobachten war, kann wohl am wahrscheinlichsten damit in Zusammenhang gebracht wer. den, daß die Salzlösung besonders bei den ansehnlich großen Dolomitbröckchen des groben Sandes auch tief in deren Inneres eindringt und in dem auferordentlich feinen Spaltwerk ${ }^{25}$ ) des hier vorliegenden Gesteins so groben Widerstand findet, dab sie nur auberordentlich langsam aufwärts steigt, während die kurzen Haarspalten in der winzigen Teilchen des feinsten Sandes viel schneller von der Salzlösung durchmessen werden können. Von diesen Haarspalten rührt es wohl auch her, daß sich die Ausbluhung nicht nur zwischen den Sandteilchen aller Sortimente ansetzt, sondern dieselben auch als zusammenhängende Kruste ohne Lücken gleichmäRig überzieht.

Wie die einfache Ueberprüfung und die weiter unten besprochene chemische Untersuchung er-

25) Ueber die vorzuggliche Spaltbarkeit kristallinischen Kalkes vg!.: W. Bag ger, Inaug.-Diss. (Königsberg 1902). 
geben, sammelt sich durch die geschilderten Vorgange schlie Blich in jedem Falle fast die ganze Salzmenge des Bodens in seiner obersten Schicht, welche so bei der Salzausscheidung in fester Form ibr $\mathrm{Vo}$. lumen vergröbern und sich dabei überhöhen muB, solange kein Uebertreten von Lösung und hierdurch auch der Ausblühung auf die Gefäbaubenwand erfolgt. Der letztere Vorgang scheint bei dem feinsten Dolomits and I mit seiner stark emporgetriebenen $\mathrm{Sal} z$ platte dadurch verhindert $z u$ sein, dab die adhäsive Anziehung zwischen den feinsten Sandteilchen und der Salzlösung größer ist als jene zwischen der Salzlösung und der GefäBwand. Dies geht auch aus der innigen Verkittung der Sand- und Salzteilchen zu der in Abb. 10 dargestellten zusammenhängenden, abhebbaren Platte hervor, deren Ausbildung aber wohl auch noch durch andere Momente unterstützt wird.

Mit abnehmender Feinheit des Sandsortimentes verringert sich zunächst, wie es scheint, die gegenseitige Anziehung zwischen dessen Teilchen und der Salzlösung sehr schnell, denn schon bei Dolomitsand II klettert die Ausblühung starkan der Gefabaubenwand herunter. Die in naturlicher Folge hiervon dünner werdende, weiter auseinander gezogene Salzdecke weist keine Ueberhöhung mehr a uf. Die geschilderten gegenseitigen Beziehungen verstärken sich nun bis zum Sandsortiment IV, wie aus Abb. 8 deutlich erkennbar ist.

Es wurde schon darauf hingewiesen, dab dann wieder mit noch mehr zunehmender Teilchengröße der Sandsortimente und zwar in der Reihenfolge der Dolomitsande V, VI und VII das Uebergreifen der Ausblühung a uf die GefäBaubenwand zusehends $\mathrm{schwächer} w i r d$, während sich neuerdings die Salzdecke auf der Salzoberfläche unter Annahme einertropfsteinarigen Ausbildung verstärkt. Ohne eine restlose Erklärung hierfür behaupten zu wollen, sei zum Verständnis dieser letzteren Ausblühungsbilder (Abb. 8 rechte Hälfte) nochmals an die zahlreichen, feins the $\mathrm{n}$ Ha a r p al ten erinnert, welche beim vorliegenden kristallinischen Dolomitsand sich in den wachsend großen Gesteinsbröckchen der fortschreitend grồber werdenden Sortimente besonders geltend machen können. Der benütate Dolomit neigte auch stark zur Porosität und war an seiner Entnahmestelle weitgehend transirersal geschiefert, also auch aus diesem Grunde mit winzigen, engsten
Kanälchen durchsetzt. Eine Folge hiervon ist nicht nur das Vorkommen der weiter oben erwähnten, außerordentlich reichen Auswitterungen auf kompaktem Bruchsteinmanerwerk aus solchem Dolomit, sondern es deutet auf diesen Zustand auch die experimentell jederzeit höchst einfach feststellbare Gewichtszunahme hin, welche ein völlig lufttrockenes Dolomitbröckchen durch längeres Untertauchen in Wasser auch nach sorgfältigem Abtrocknen noch erkennen läbt. Es dringt also durch kapillare Kräfte, welche die Anziehung zwischen GefäBglaswand und Salzlösung ausgleichen, letztere in das lanere der Teile der groben Sandsortimente ein und bahnt sich langsam, den Berührungsstellen derselben folgend, ebenfalls den Weg nach aufwärts, wo sie an der Bodenoberfläche infolge der Verdunstung das Salz tropfsteinartig absetzt und eine unebene Decke bilden hilft, die stellenweise umso stärker überhöht erscheint, je unebener gleich anfangs die salzfreie Sandoberfläche bei zunehmender Gröbe der Sandteile sich ausbildete.

Wenn schon hiermit in groben Unrissen auf einige Möglichkeiten von physikalischen Vor gängen hinzuweisen versucht wurde, welche bei der Entstehung der vorliegenden Ausblühungen wahrscheinlich mitwirkten, so erübrigt es, noch aufzuklären, weshalb in ke inem einzigen -Falle die Effloreszenz die dem NaCl bei seiner Abscheidung aus wäseriger Lösung eigene Kristallform der vierseitigen, innen hohlen, tesseralen Pyramidchen a f weist. Wir wissen aus zahlreichen Untersuchungen, daß derartige Veränderungen in, der Kristallanordnung durch fremdartige $B$ eimengungen zu der Lösung hervorgebracht werden, woraus Kristallisation erfolgt. Einige solche lassen sich bei den hier voriliegenden Salzausbluhungen schon von vornherein bezeichnen. So mupten etwas Kalziumbikarbonat und auch Magnesi u $\mathrm{mbik}$ a rbon at aus dem im nassen Zustand längere Zeit an der luft stehenden Boden in dessen Lösung übergehen. Auch Kalzi um $k$ arbonat an sich ist etwas in Wasser unter deutlich alkalischer Reaktion löslich. Es mag zwar fraglich erscheinen, ob diese geringen Beimengungen einen in Beiracht kommenden Einflub in bezeichneter Richtung auszuüben vermögen. Jedenfalls aber darf. datan erinnert werden, daß sie sich beim Eintrocknen des Bodens wieder in uniöslicher Form abscheiden und dadurch in gewissen Grenzen Hemmungen verursachen kömnen. Auch dis mattweiBe Farbe 
der Ausblühungen kann mit dieser Verunreinigung zusammenhängen.

Es wurde aber auch schon besprochen, daß auberdem humose Hydrosole mit Neigung zu leimiger Konsistenz mit angelagerten Mineralstoffen schon in der wässerigen Lösung des nicht salzversetzten Dolomitsandes festzu- stellen waren. Zur Gewinnung eines genaueren Einblicks wurden außerdem auch noch die einzelnen Sortimente nach disscr Richtung untersucht und zwar durch Behandlung von je $100 \mathrm{~g}$ mit $1000 \mathrm{ccm}$ heißem Wasser ${ }^{26}$ ) und Bestimmung der Rückstände. Es enthielten die Sortimente die in Tab. II angegebenen Rückstandsmengen.

Tabelle III.

\begin{tabular}{ll|c|c|c|c|c|c|c|c|}
\hline & & I & II & II & IV & V & VI & VII \\
\hline Insgesamt. & . . . . . g & 0,097 & 0,060 & 0,032 & 0,014 & 0,015 & 0,014 & 0,015 \\
Glührückstand &. &. & 0,028 & 0,018 & 0,007 & 0,003 & 0,004 & 0,004 & 0,004 \\
Glühverlust . . . . . . & 0,069 & 0,042 & 0,025 & 0,011 & 0,011 & 0,010 & 0,011
\end{tabular}

Außer dem Ergebnis, daß eine wesentlich höhere Lösungsfähigkeit als bei reiner Dolomitsubstanz vorliegt und daB die feinsten Sortimente die meisten wasserlöslichen Stoffe enthalten, kann diesen Zahlen entnommen werden, dab die durch den Glühverlust angedeutete wasserlosliche humose Substanz ebenfalls mit zunehmender Feinheit der Sortimente in immer reichlicheren Mengen auftritt. Dieser Befund steht im Einklang mit der auch bei der einfachen mechanischen Ueberprüfung gewinnbaren Ueberzeugung, dab der Gehalt an sichtbaren humosen Teilchen überhaupt mit zunehmender Feinheit des Sandes wächst, also bei Dolomitsand I am größten ist.

Durch den Zusatz von $\mathrm{NaCl}$ zu den Sortimenten wird nun sichtlich die Löslichkeit der humosen Substanzen noch ver me hrt. Eine genaue Bestimmung hierüber konnte zwar infolge experimenteller Schwierigkeiten (hierher zählt die beginnende Verflüchtigung von $\mathrm{NaCl}$ beim starken Erhitzen und Glühen) nicht durchgeführt werden. Allein die zähe, nun ganz leimartige Beschaffenheit der Eindickungen der wässerigen Lösungen der salzversetzten Sande, der auffallende Geruch, die gelbe Farbe sprachen dafür, daß durch den $\mathrm{NaCl}$ Zusatz entweder neue Hydrosole humoser Art in Lösung gehen oder mindestens jene, weiche bereits in den wässerigen Lösungen der Dolomitsande nachgewiesen worden waren, eine weitgehende Veränderung erleiden konnten. Es lag die Beschaffenheit von Gummiarabikum, Gelatine u. dgl. vor. Hierdurch ist aber ein Erklärungsgrund dafür gewonnen, daB die $A u s$ -

26) Mit der angewandten Wassermenge konnte selbstredend nicht die absolute, sondern nur eine relative Löslichkeit auf gleicher Grundlage in allen Fallen crmittelt werden. blühungen keine Spur von echter $\mathrm{NaCl}-\mathrm{Kr}$ istallisation erkennen lieben. Denn die Einwirkungen derartiger Kolloide in gewissen Mengenverhältnissen auf das Vermögen zum Kristallisieren sonst an sich dazu befähigter Lösungen sind bekannt ${ }^{27}$ ). So ist beispielsweise besonders charakteristisch, daB J. A lexander durch Beimischung von Gelatine zu Sahne beim Gefrieren dieser ein vollkommen weiches Sahneneis erhielt, welches auf der Zunge keine Spur von Eiskriställchen erkennen läßt. Gipslösung, mit genügend Gelatinelösung versetzt, zeigte unter dem Mikroskop keine Spur von Kristallisation. Auch die Salzdecken auf den mit Humussolen durchsetzten Dolomitsanden zeigten nicht die geringste kristallinische Struktur. Aber auch die Kolloide hinwiederum können, wie Liese $\mathrm{gan}^{28}$ ) ermittelte, in ihrer trockenen Abschcidungsform durch die Einwirkung von Salzen sehr eigentümliche Gestalten annehmen, welche Verf. teilweise auch hier an der Oberfläche der Salzkrusten glaubt angedeutet vorgefunden $z u$ haben. Daraus, dab auch bei den gröbsten Sortimenten, die nur noch sehr geringe Mengen von Hunuskolloiden aufwiesen (Tabelle III), die Ausbildung einer derartigen Salzkruste ohne Kristallflächen ebenfalls noch stattgefunden hatte, kann geschlossen werden, daß die Wirkung der Humuskolloide in diesem Sinne eine sehr kräftige sein muß. Und dak überhaupt bei diesen grofen, sich äußerlich rein mineralisch darstellenden Gerölistïcken noch das Vorhandensein von wasserlöslichen Humuskolloiden nachgewiesen werden kann, rührt wohl wieder

27) W. M. Ord, Der Einfluß von Kolloiden auf die Kristallform und Kohäsion (Zeitschr. Kr. 4, 619 bis 621,1880 ). J. A l ex a n d e r, Die Wirkungen von Kolloiden auf die Kristallisation (Koll.-Zeitschr.4, 86 usw.).

28) R. E. Liesegang, Ueber die Formung von Gelatine durch Salzniederschläge und Kristalle (Koll.Zeitschr. 1,364). 
von deren inneren Haarspalten her, in welche die humose Lösung des Gesamtbodens schon in der Natur eindringen konnte, um dort nach dem Austrocknen festgehalten $\mathrm{zu}$ werden, bis wieder eine, wenn auch vielleicht nur teilweise Auslaugung durch Wasser stattfindet:

Endlich haben wir in diesem engen $S$ paltennetzder Dolomitteilchen auch einen Erklärungsgrund für die durchwegs plattenartige Ausbildung der Salzdecke auf allen Sandsortimenten zu erblicken. Durch dieses feinverteilte System engster Hohlräume ist der Salzlösung Gelegenheit gegeben, nicht nur in den $Z$ wischenräumen zwischen den einzelnen. Dolomitteilchen emporzuklettern, sondern auch in den kapillaren Leitungsbahnen der Dolomitteilchen selbst a ufzusteigen. So füllen sich durch die Verdunstung der Lösung nicht nur die Lücken zwischen den benachbarten Teilchen der Sandoberfläche aus, sondern diese überziehen sich selbst mit Salz und machen dadurch die Decke desselben auf dem Sande zu einer zusammenhängenden. Je feiner der Sand ist, desto mehr werden die zwischen und auf den Dolomitteilchen abgesetzten Salzmengen ineinanderfließen und desto weniger größere Unebenheiten wird die Ausblühung aufweisen (Dolomitsand I, Abb. 8), je gröbere Dolomitteilchen der Ueberziehung mit Salz unterliegen, desto schwieriger wird die Ausfüllung der groben Unebenheiten an der Sandoberfläche und desto mehr nimmt die Ausblühung höckerigen Charakter an (Dolomitsanu VII, Abb. 8).

Damit glaubt Verf. in großen Umrissen das Wesentliche, was sich zur Erklärung der beobachteten Ausblühungserscheinu $\mathrm{g}$ e n vorbringen läbt, angeführt zu haben. Es konnten aber während der lang andauernden und wiederholt durchgeführten Versuche auch noch eine Reihe weiterer Beobachtungen und Ueberlegungen gepflogen werden, auf welche mit Vorbehalt nachstehend ebenfalls verwiesen wird. Sie beziehen sich alle auf die oben beschriebenen $\mathrm{h} u \mathrm{mosen} \mathrm{Kollo}$ ide in den wässerigen Auszügeı der Dolomitsande.
So wird das starke Emportreiben der Salzdecke auf dem feinsten Dolomitsand 1 unter Volumvergrößerung der ganzen Sandmasse noch verständlicher, wenn man bedenkt, daß die Dampfspannung des teilweise auch schon im Innern der Sandmasse verdunstenden Wassers höher steigen und deshalb aufblähender wirken kann, wenn dem Entweichen des Dampfes durch die leimartige Konsistenz des nassen Sandbreis ein erhöhter Widerstand entgegengesetzt wird. Die Reichlichkeit der Kolloide bei den feinsten Sortimenten in der Lösung macht auch die vollkommen fehlende Adhäsion zwischen dieser und der GefäBauBenwand, welche vollkommen frei von Ausblühungen bleibt, verständlicher, denn die spezifische Zähigkeit der Salzlösung wird dadurch erhöht. Mit Abnahme der Feinheit der Teilchen bei den gröber werdenden Sanden zeigt sich dann ein Zurücksinken der Salzkruste, nicht nur deshalb, weil der Wasserdampf durch die größeren Hohlräume leichter Ausgang findet, sondern auch die Zähigkeit der Salzlösung durch verminderten Gehalt an Hydrosolen humoser Art abnimmt.

Lehrreich erscheint auch ein Vergleich der in Tabelle III angegebenen Rückstandsmengen der wässerigen Lösungen a us den Sanden mit den ermittel. ten Gewichten der Rückstände aus den salzversetzten Sanden, welche durch separate Ausblühungsversuche in Porzellanschalen ermittelt wurden. Unter Berücksichtigung-der in Tabelle III enthaltenen Zahlen würden sich bei Hinzurechnung der beim Ausblühungsversuch jeweils auf $100 \mathrm{~g}$ zugesetzten $3,000 \mathrm{~g} \mathrm{Na} \mathrm{Cl}$ die in der folgenden Tabelle IV unter 3 . angegebenen Rückstandsmengen aus der salzhaltigen Lösung erwarten lassen, welchen aber die in Wirklichkeit bei vollkommener AussüBung erhaltenen Rückstände letzterer Abstammung, die in Tabelle IV unter 4. aufgeführt sind, keineswegs entsprechen.

Die feststellbaren Rückstandsmengen ergaben demnach gegenüber den erwartbaren einen Verlust, der wegen der Größe und der Beharr-

Tabelle IV.

\begin{tabular}{|c|c|c|c|c|c|c|c|}
\hline & I & II & III & IV & V & VI & VII \\
\hline 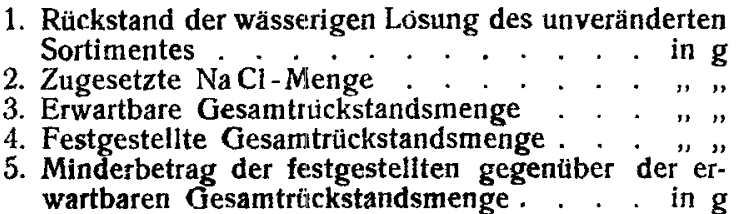 & $\begin{array}{l}0,097 \\
3,000 \\
3,097 \\
\mathbf{3 , 0 6 2} \\
\mathbf{0 , 0 3 5}\end{array}$ & $\begin{array}{l}0,060 \\
3,000 \\
3,060 \\
3,019\end{array}$ & $\begin{array}{l}0,032 \\
3,000 \\
3,032 \\
\mathbf{2 , 9 5 6}\end{array}$ & $\begin{array}{l}\mathbf{0}, 014 \\
3,000 \\
3,014 \\
\mathbf{2 , 9 7 4}\end{array}$ & $\begin{array}{l}0,015 \\
3,000 \\
3,015 \\
\mathbf{2 , 9 8 1}\end{array}$ & $\begin{array}{l}0,014 \\
3,000 \\
3,014 \\
\mathbf{2 , 9 9 8} \\
\mathbf{0 , 0 1 6}\end{array}$ & $\begin{array}{l}0,015 \\
3,000 \\
3,015 \\
\mathbf{3}, 002\end{array}$ \\
\hline
\end{tabular}


lichkeit, womit er auftrat, nicht mehr auf Fehlerquellen, die bei Bodenuntersuchungen bekanntlich niemals ganz $\mathrm{zu}$ beseitigen sind, allein zurückführbar ist. Der Verlust war bei den feineren Sortimenten bedeutender als bei den gröberen, aber beim feinsten Dolomitsand I nicht am größten, sondern von Sortiment I-III ansteigend und dann wieder abnehmend.

Es ist naheliegend, für diese Verluste eine Deutung zu suchen. Falsch wäre die Schlubfolgerung, daB die Löslichkeit verschiedener Stoffe, die ursprünglich aus den salzlosen Sanden leicht in das reine Wasser übergingen, gegenüber der kräftigen $\mathrm{NaCl}$-Lösung eine Einbuße erlitt. Im Gegenteil, wir wissen, dal $\mathrm{NaCl}$ lösend auf Gips, Phosphate, Kaik, Magnesia, Kali und Humussubstanzen wirkt, kurzum, daß sich die Löslichkeit vermehrt, wenn den in Betracht kommenden Salzen, wie beispielsweise auch hier, kein Ion gemeinsam ist. Hingegen erscheint es nach dem gegenwärtigen Stand unserer Kenntnisse schon nicht mehr aussichtslos, die Gegenwart der gelatioosen Humuskolloide auch als Ursache der ermittelten Gewichtsverluste anzusprechen. Diese humosen Verbindungen, die von einer Reihe von Forschern als mineralorganische Absorptionsverbindungen aufgefaßt werden, sind Kolloidkomplexe, welche dadurch in wechselndster Zusammensetzung entstehen können, daß sich ihnen mineralische Verbindungen in abweichenden Mengen anlagern. Es ist nachgewiesen ${ }^{29}$ ), das durch die Gegenwart solcher Verbindungen Bodensalze Zersetzungen erleiden. So werden Chloride, die im vorliegenden Falle reichlich vorhanden waren, unter Absch e idung von $\mathrm{HCl}$ und Freiwerden der Base, die der Absorption unterliegt, zerlegt. Wenn auch von der gebildeten $\mathrm{HCl}$ angenommen wird, daB sie sich mit weiteren, leicht zersetzbaren Stoffen des Bodens, in vielen Fallen mit $\mathrm{CaCO}_{3}$, umsetze, so bleibt doch $z u$ berücksichtigen, daB dabei wieder Chloride entstehen, welche durch die Humuskolloide oder vielleicht schon ihre Stammsubstanzen neuerdings noch wiederholt zerlegt werden können, so dab ein Gewichtsverlust durch teilweises Entweichen von $\mathrm{HCl}$ eintreten kann und den Substanzverlust noch vermehrt, der durch das $F r$ iw erden von $\mathrm{CO}_{2}$ bei der Umset $z$ ung $z$ wischen

29) Eichlo orn, Einige Beiträge zu den Absorptionserscheinungen in den Ackererden (Landw. Jahrbücher 4,21, 1875) A. Baumann und $E$. Gully, Mirteilungen der Kgl. Bay. Moorkulturanstalt 4, 36 usw. gelöstem $\mathrm{CaCO}_{3}$ und $\mathrm{HCl}$ eintreten muß. Auf ähnliche Weise kann aber auch durch die Humuskolloide ohne Mitwirkung von $\mathrm{HCl}$ in Wasser gelöstes $\mathrm{Kalzi}$ mkarbonat unter Abspaltung von $\mathrm{CO}_{2}$ zersetzt werden. In den Hohlräumen der salzversetzten Dolomitsande können daher auber der gewöhnlichen Luft und auBer Wasserdampf gewisser Spannung auch $\mathrm{CO}_{2}$ und Dämpfe von $\mathrm{HCl}$ vermutet werden, die teils beim Auflösen der ausgeblühten Salzkrusten, teils beim Eindampfen der wässerigen Lösung entweichen, in jedem Falle also Gewichtsverlust verursachen. Tatsächlich konnte vom Verf. ganz bestimmt festgestellt werden, dab der salzversetzte feinste Dolomitsandl, wenn er sich in einem Porzellanschälchen befand, deren Form eben den hermetischen Abschlub der Sandteilchen durch die sich wie ein undurchdringlicher Deckel darauf lagernde Salzkruste ermöglicht, deutlichste andauernde Gasentwicklung beim Uebergielen und Anrühren mit Wasser zeigte. $\mathrm{Ob}$ nun dieses gleichmäbige Aufperlen von durch Kalkzerfall gebildeter $\mathrm{CO}_{2}$ oder soleher durch Einwirkung von $\mathrm{HCl}$ auf Kalk entstehender herrührte oder von beiden zugleich, mag dahingestellt bleiben. Jedenfalls lag keine Verwechslung vor mit der beim Uebergießen von Böden mit Wasser häufig vorkommenden Schaumbildung, die wohl mit dem Entweichen von Luft und anderen Gasen aus einer Art kolloiden Wabengewebes nach va n Bem. melen ${ }^{30}$ ) zusammenhängt, ähnlich wie auch Corn ${ }^{31}$ ) die Festhaltung gasförmiger Bestandteile im Boden auffaBt. Vielmehr konnten die Gasbläschen deutlich in ihrer Entwicklung, ihrem Aufsteigen und Wiederverschwinden an der Lösungsoberfläche beobachtet werden. $\mathrm{DaB}$ übrigens die Lősung auch noch reichlich Gas absorbiert enthielt, war aus dem fortgesetzten Aufperlen während des Eindampfens und der gewaltsamen AusstoBung von Bläschen aus der Eindickung der Lösung zu entnehmen, welche schlieblich einen Rückstand mit blatternarbenähnlichen Unebenheiten hinterlieh, wobei jeder zuletzt entwichenen Gasblase deutlich eine dafür zurückbleibende Vertiefung entsprach. Schon beim Dolomitsand II mit seinen größeren Hohlräumen, welche gebildete Gase und Dämpfe leichter ent weichen lassen können, und mit seinem geringeren Gehaltan wasserlöslichen

90) J.M. va n Bem me len, Die Absorption (Dresden 1910), Steinkopff, 535 .

ni) F. Corn a, Der „Tongeruch" u. andere Gerùche der Hydrogele des Mineralreichs (Koll.-Zeitschr. 4, 90). 
humosen Kolloiden (vgl. Tabelle III) war beim Ausblühungsversuch in Porzellanschalen dieses Aufperlen kaum mehr bemerkbar, schon beim Dolomitsand III war es uberhaupt nicht mehr sichtbar vor handen. Trotzdem. wäre aber die Annahme unrichtig, dab im letzteren Falle überhaupt keine $\mathrm{NaCl}$ Zersetzung mehr möglich war. Denn die aus Tabelle IV sprechenden Verluste, welche bei Sortiment III -VI sogar höher sind àls die Rüçkstandsmenge der wässerigen Lösung des unveränderten Sortimentes, waren sehr deutlich. Es ist eben $z u$ bedenken, daB auBer dem wasserlöslichen Anteil von Humuskolloiden auch noch ein Kern unlöslicher solcher Bestandteile zugegen ist, der ebenfalls $\mathrm{NaCl}$ spaltend zu wirken vermag. Und tatsächlich zeigte sich beim Eindampfen auch der wässerigen Lösungen der salzversetzten groben Sortimente noch deutlich AusstoBung von Gasbläschen aus der zäher werdenden Flüssigkeit.

Bemerkenswert ist auch, daB sich das weiter oben erwähnte Aufperlen selbst bei Dolomitsand I dann nicht einstellte, wenn die Ausblühung in den niederen Glaswannen (Abb. 8, $9,10)$ vorgenommen wurde. In diesen konnte sich auf der Sandmasse keine nach oben hermetisch abschliebende Salzdecke ausbilden, denn der aufgetriebene Sand (Abb. 8 I, Abb. 9) überragte die GefäBränder und lieb die wahrscheinlich gebildeten Gase seitwärts und nach oben entweichen, während in der Porzellanschale die an ihrer Innenfläche noch hinaufkriechende Salzkruste keinen Ausweg zum Entweichen von Gas offen läBt, wenn auch der darunter befindliche Sand sein Volumen verändert.

Damit sind aber die möglichen Quellen der Substanzverluste in der wässerigen Bodenflüssigkeit des $\mathrm{NaCl}$ versetzten Dolomitsandes noch nicht erschöpft. Selbstredend müs se n bei der besprochenen Zersetzung von Sal. zen durch $\mathrm{Humuskolloide} \mathrm{auch} \mathrm{diese}$ eine Umänderung erleiden. Bekantlich wissen wir darüber nur sehr wenig. Die absorptiv schwach gesättigten Humuskolloide gehen dabei ganz oder teilweise in absorptiv stärker gesättigte durch Anlagerung von Basen, hier von Kalk (Magnesia) und Natron über. Daß aber dabei auch sonst noch Veränderungen mit den Kolloiden, beispielsweise durch Einwirkung des Luftsauirstoffs, von Konzentrationsänderungen usw. vor sich gehen, erscheint wahrscheinlich. So kann, wie bereits erwähnt, schon beim Eindampfen der wässerigen Lösung des unveränderten Gesamt-Dolomitsandes, ganz be- sonders aber bel dem der feinsten Sortimente mit ihrem höheren Humusgehalt, beobachtet werden, dak die vorher gelösten Kolloide unter Zunahme der Bräunung in einen wasserunlöslichen Zustand übergehen. Sie werden ganz oder teilweise ausgeschieden. Und die wasserunlöslichen Trübungen erweisen sich als mit $\mathrm{HCl}$ nicht brausende mineralorganische Verbindungen mit hauptsächlich angelagertem Kalk. Solche Erscheinurigen waren aber auch bei der Untersuchung der Lösungen der salzversetzten Sande beobachtbar und können vielleicht zurückgeführt werden auf die Ausflockung ursprünglich als $\mathrm{Hydrosole} \mathrm{gelöster}$ Humuskolloide in Gelform durch den starken $\mathrm{NaCl}-\mathrm{Geh}$ alt der Bodenlösung. Fest steht, daß beim Behandeln der salzversetzten Dolomitsande mit Wasser ein Teil der Kolloide im ausgeflockten Zustand verharrt und erst wieder als Sol beweglich wird, wenn bei der fortgesetzten Auswaschung der betreffende "Schwellenwert" der Salzlösung unterschritten wird. Es konnte in oft wiederholten Versuchen beim Auswaschen die wohlbekannte Erscheinung beobachtet werden, daf nach. Ablauf von anfangs durchaus kiarem Filtrat sich die Waschwasser wieder trübten und zwar nicht allmählich, sondern ziemlich plötzlich und zwar un!so stärker, je feiner das untersuchte Sandsortiment war. Diese trüben Waschwasser wurden dann von der Vereinigung mit dem klaren Filtrat ausgeschlossen und für sich aufgefangen, filtriert und untersucht. Und erst dieses Filtrat ward dem ursprünglichen wieder beigefügt. Die Trubung erwies sich dabei als Humtiskolloid mit in der Hauptsache, aber nicht ausschlieBlich angelagertem Kalk. Ein Brausen mit $\mathrm{HCl}$ trat erst nach dem Glühen des Rückstandes der eingedampften trüben Flüssigkeit ein, konnte hingegen in dessen ungeglühtem Zustand nicht festgestellt werden.

Mehrere Verlustquellen ${ }^{32}$ ) können demnach namhaft gemacht werden, welche eine Verringerung der feststellbaren Gesamtrückstandsmengen der wässerigen Lösung aus den salzversetzten Dolomitsanden gegenüber den erwartbaren erklärlich machen. Und für alle kann eine zunehmend starke Wirkung bei den feineren Sortimenten, die stärkste beim Dolomitsand I vorausgesetzt werden. Hiermit stimmen aber die Zahlen der Tabelle IV nicht überein, denn sie zeigen, dab der feststellbare Verlust von Sor-

32) Auch an die von Berthelot. herrihrende Erklärtung der Bildung unlosticher humoser Allaliverbindunger kônnte gedacht werden. 
timent I - III zunahm und erst von da bis Sortiment VII wieder abnahm. Aber auch dieser Widerspruch ist erklälich, denn es spielen sich im salzversetzten Dolomitsand nicht allein Vorgänge $a b$, welche Substanzverluste der wässerigen lösung bedingen, sondern auch Unsetzungen anlaslicher Bodenbe. standteile in lösliche. In dieser Hinsicht wird die durch Humuskolloide aus Chioriden abgespaltete $\mathrm{HCl}$ im Dolomitsand selbstredend nie ganz wirkungslos bleiben könmen ${ }^{33}$ ). Es sind aber vielleicht auch andere AufschlieBungen nicht undenkbar. Das Gesantergebnis ist aber in diesem Falle immer ein $\mathrm{Zu}$ wachs an Rückstandsmengeder wäs erigen Bo. denlosung. Dies deuten auch die folgenden, in Tabelle $V$ zusammengestellten Zahlen an. Es enthielt beispielsweise auf je $100 \mathrm{~g}$ der Boden in wässeriger Lösung die in Tabelle $V$ angegebenen Ruckstandsmengen.

Tabelle V.

\begin{tabular}{|c|c|c|c|c|c|c|}
\hline \multirow{2}{*}{ Sortiment } & \multicolumn{5}{|c|}{ Mit $\mathrm{NaCl}$ versetzt } & \multirow{2}{*}{$\begin{array}{l}\text { Nicht mit } \\
\mathrm{NaCl} \text { versetzt } \\
\text { Gluhrickstand } \\
\text { (nach Tabelle III }\end{array}$} \\
\hline & $\mathrm{CaO}$ & $\mathrm{MgO}$ & $\mathrm{Al}_{2} \mathrm{O}_{3}$ & $\mathrm{Fe}_{\mathrm{g}} \mathrm{O}_{3}$ & $\begin{array}{l}\text { Summe der } \\
\text { bestimmter } \\
\text { Oxyde }\end{array}$ & \\
\hline $\begin{array}{cc}\text { Dolomitsand I } & \text { II } \\
" & \text { " }\end{array}$ & $\begin{array}{l}0,018 \\
0,016 \\
0,008\end{array}$ & $\begin{array}{l}0,009 \\
0,003 \\
\text { Spur }\end{array}$ & $\begin{array}{l}0,006 \\
\text { Spur } \\
\text { Spur }\end{array}$ & $\begin{array}{c}\text { Spur } \\
0 \\
0\end{array}$ & $\begin{array}{l}0,033 \\
0,019 \\
0,008\end{array}$ & $\begin{array}{l}0,028 \\
0,018 \\
0,007\end{array}$ \\
\hline
\end{tabular}

Es war also schon ohne Hinzurechnurg dez nicht bestimmten Basen und Säureradikale in den wässezigen Lösungen der salzversetzten Dolomitsande die Summe der Gewichte der feuerfesten Metalloxyde gröber als die Menge des gesamten Glührückstandes der nicht $\mathrm{NaCl}$ haltigen wässerigen Lösungen, was nur so er" klärt werchen kann, daß im salzversetzten Sand während des Ausblühungsvorganges neue Bodensubstanz in wasserlöslichen Zustand überging.

Im $\mathrm{NaCl}$-haltigen humosen Dolomitsand finden also Gewichtsverluste und Gewichtszuwachse an wasserlöslicher Substanz nebeneinander statt. So kann es kommen, dab der nach obigen Mittellungen besonders zu Gewichtsverlusten neigende Dolomitsand I doch nicht den höchsten Gesamtverlust aufweist, weil ein teilweiser Ausgleich Gurch Substanzzuwachs in stärkeren Grade stattzufinden scheint als bei den Dolomitsander II und MI, wobei daran erinnert sei. daB beim Anrubren milt Wasser der Dolomitsand I am reichlichsten Gasbläschenentwicklung zeigte, Dolomitsand II vit weniger und Dolomitsand III gar nicht mehr.

Es erscheint fraglich, ob die als Sole oder Gele in den mit Wasser behandelten salzver setzten Dolomitsander enthaltenen Humuskolloide ausschlieflich von den schon im unveranderten Sand enthaltenen wasserlöstichen humoseu Verbindungen abstammen oder ob sie ihren Ursprung nicht auch teilweise der Einwirkung der NaCl-Losang auf an sich wasser- unlösliche Humusstoffe der Dolomitsande verdanken, die wenigstens beim Dolomitsand I schon makroskopisch durch einfache Ueber* prüfung reichlich erkannt werden konnten.

Einen Hinweis endlich dafür, daß bei den beschriebenén Vorgängen, deren Erörterung hiermit beschlossen sei, vielleicht nicht nur die Menge der humosen Kolloide eine Rolle spielen kann, sondern auch eine verschiedene Reaktionsfähigkeit derselben vorliegt, können wir daraus entnehmen, dab der Salzkruste auf dem feinsten Dolomitsand I ein reversibles Kolloid beigemengt war, daß die Reversibilität aber immer mehr abnahm, je gröber das Sortiment. war, von dem die Salzkruste abstammte. Denn wurden ganz reine Teilchen der Salzkruste vom Dolornitsand I auf einem Uhrglas mit einigen Tropfen Wasser übergossen und diese der Verdunstung uberlassen, so schieden sich wieder die gleicien formlosen Salzgebilde ab, welche schon der ursprünglichen Salzkruste das Gepräge verliehen. Wurde die Salzkruste der gröbsten Sortimente in der gleichen Weise geprüft, so schieden sich nach der Verdunstung auf dem Uhrglas oder dem Platinblech deutlich vierseitige, tesseraie $\mathrm{NaCl}$-Pyramidchen ab unter gleichzeitiger Hinterlassung einer schwachen Trubung an den Rändern des Rückstandes, die sich beim Erhitzen schwärzte. Bei den mitt-

53) Vgl. hierzu H. Puchner, Untersuchungen wher de Transport der loslichen Salze bei der Yiasserbewegtng im Boden (Forsch. a. J. Geb. d. Agrikulturphysik 18, Separatabdruck, 18). 
leren Sortimenten bestanden die betreffenden Rückstände aus einem Gemenge von $\mathrm{NaCl}$ Pyramidchen und formlusen Salzegebilden.

Von Interesse erschien Verf. aber doch noch die Feststellung, ob dic an der Oberfläche der Dolomitsande entstehende Saixkruste alle in der Bodenmasse vorhanden gewesenen löslichen Verbindungen enthält oder ob auch in tieferen Schichten noch ein Anteil davon vorzutinden ist. Die leichte Abhebbarkeit der Salzplatte bei Dolomitsand 1 würde für die erstere Ansicht sprechen, die Erscheinung, dab die Teilchen der unteren Lagen bei allen Dolomitsanden auch noch eine deutlich wahrnehmbare Verkittung erkennen ließen, läbt jedoch vermuten, dak die löslichen Bestandteile nicht restlos in die oberflächliche Salzkruste wandern. Zur Entscheidung wurden je $100 \mathrm{~g}$ der Salzkruste einerseits, der Sandmasse am Grunde des Gefäßes andererseits, quantitativ untersucht und zwar bei jenem Sortiment, das sowolhl die Ausbildung der Salzdecke wie das Zusammenbacken der untersten Lagen am deutlichsten zeigte, nämlich bei Dolomitsand I. Es enthielten je $100 \mathrm{~g}$

Tabelle VI.

\begin{tabular}{l||c|c}
\hline & $\begin{array}{c}\text { Salz- } \\
\text { decke }\end{array}$ & $\begin{array}{c}\text { Tiefste } \\
\text { Sandlagc }\end{array}$ \\
\hline Gesamtrückstaud . . . in g & 20,703 & 0,507 \\
Na Cl, aus Cl berechnet . " " & 19,860 & 0,419 \\
$\begin{array}{c}\text { Rest, einschließlich Humuskol- } \\
\text { loid . . . . . . . in g }\end{array}$ & 0,843 & 0,088
\end{tabular}

Hieraus ergibt sich, dah auch in den unteren Lagen des feinsten Dolomitsandes in dem Augenblicke der Gesamtaustrocknung noch etwas $\mathrm{NaCl}$ oder ein anderes durch Unsetzung entstandenes Chlorid zurückgehalten wird, was im Hinblick auf die Wechselwirkung, zwischen den unlöslichen Bestandteilen des Sandes and den $\mathrm{NaCl}$-Teilchen erklälich erscheint. Obwohl keine Sonderbestimmung der Humuskolioide vorgenommen wurde und vorgenommen werden konnte, machen die Zahlen ferner wahrscheinlich, dab das Verhaltnis von $\mathrm{NaCl}$ zu Humuskolloid in den untersten Sandschichten enger ist als in der Salzdecke, d. h. dab die Humuskolloide langsamer aufwärts steigen als $\mathrm{NaCl}$. In die oberflächliche Ausblühung gelangen die Humuskolloide aber doch, wie aus der Schwärzung der Salzdecke beim Gluhen hervorgeht.

\section{Ausblühungen}

auf schwach lehmigem, glimmerhaltigen Quarasand.

Der Versuch begann am 2. Oktober 1914. Die einzelnen Sortimente verhielten sich wie folgt :
Beginn der
Ausbluhung:
I 20. Dezember
Beginn der
Ausbluhung:
II 15. Dezember
IV 14. November
III 26. November
$\mathrm{V}$ 5. November
VI 27. Oktober.

Mitte Januar 1915 waren die Ausblühungen auf allen Sortimenten sichtlich vollendet. Das Bild, welches sie boten und das in Abbilung 11 und 12 dargestellt ist, zeigte folgende Eigentümlichkeiten:

Tabelle VII.

\begin{tabular}{|c|c|}
\hline 1 & $\begin{array}{l}\text { Unregelmäßig verteilte, weiße, melllartige Aus- } \\
\text { blïhung mit großeren Fehlstellen. Dazwischen } \\
\text { reichlich längliche, wulstformige Auftreibungen } \\
\text { ohne Ausbliahung mit darunter befindlichen } \\
\text { blasenartigen Hohlräumen. Kein Herabkletlem } \\
\text { der Ausblühung an der Gefafaubenwand. }\end{array}$ \\
\hline II & $\begin{array}{l}\text { Spärlich Stellen mit mehlartiger Aushlihung. } \\
\text { Wulsfartige Auftreiburgen nur noch schwach } \\
\text { angedeutet. Schwaches Hetabklettern der Aus- } \\
\text { blthungen an der GefaBaubenwand. }\end{array}$ \\
\hline III & $\begin{array}{l}\text { Formlose, schwach durchsichtige, nur an den } \\
\text { GefäBrändern stellenweise weiBe Kruste von } \\
\text { geringer Dicke auf der ganzen Oberfläche des } \\
\text { Sandes. Stärkeres Herabklettern der Kruste an } \\
\text { der GefäBaußenwand. }\end{array}$ \\
\hline IV & $\begin{array}{c}\text { Formlose, schwach durchsichtige düne Kruste } \\
\text { mit gleichmäßig verteilten weißen Stellen } \\
\text { Starkes Herabklettern der Kruste an der Gela? } \\
\text { außenwand. }\end{array}$ \\
\hline V & $\begin{array}{l}\text { Wie bei } I V \text {, aber noch stärkeres Herabiklettern } \\
\text { der formlosen Kruste an der GefaBaufenwand. }\end{array}$ \\
\hline VI & $\begin{array}{c}\text { Wie bei V, jedoch Herabklettern der formiosen } \\
\text { Salzkruste iber die gesamte GefäßauBenwand, } \\
\text { ja sogar iber die Unterlage des Gefäbes hin- } \\
\text { weg. }\end{array}$ \\
\hline
\end{tabular}

Fassen wir wieder kurz das Typ is che aller Ausblühungen zusammon, so können wir die geringe Hohenausdehnung betonen und dabel die düne, hautartige Ausbildung mit mehlartig weiben Inseln bei den feineren Kornsortimenten hervorheben, während die stärkere, durchscheinende Kruste mit gleichmaig verteliten weiben Stcllen bei dengrö. beren Sorten auffält. Sehr charakteristisch ist wieder die Ausbluhnng auf dem feinsten Sortiment 1 des lehmig glmmerigen Sandes. 


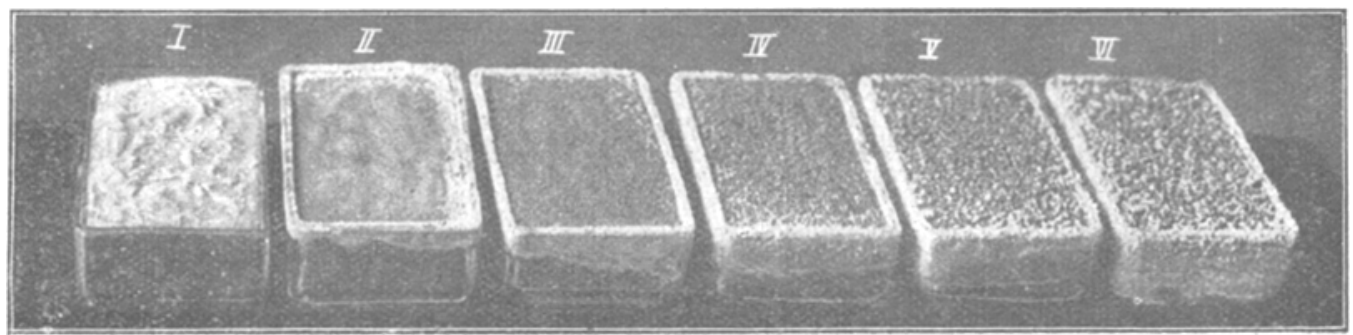

Abb. 11

Ausblithungen auf lehmig glimmerigem Quarzsand mit 3 Gew.-Proz. $\mathrm{NaCl}$.

Ihre Kennzeichnung besteht in der regellosen Zerstreung kleinerer Stellen mit weibem pulverigen Anflug $z$ wischen faltigen Wulsten der Sandoberfläche (Abb. 12). -Das selbsttätige Bêrsten dieser Auftreibungen an einigen wenigen und dabei winzigen Stellen ergibt ebenso wie die eingehendere mechanische Untersuchung, daß unter derartigen Unebenheiten Hohlräume ausgebildet sind, welche eine dünne Haut überzieht.

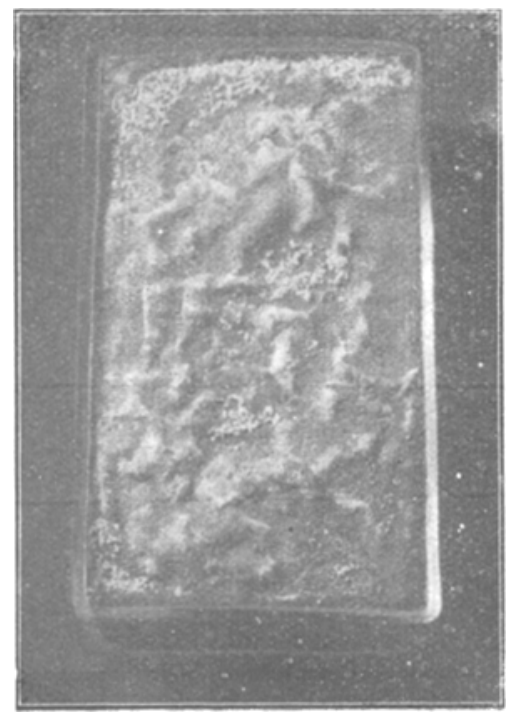

Abb. 12

Ausblikhung auf Sortiment I des lehmig glimmerigen Quarzsandes mit 3 Gew.-Proz, Na Cl.

Die Ursache der Wulstentwicklung ist in B1asenbiliungen unmittelbar unter der Sand. oberfiache zu suchen. Außerdem findet ein Uebergreifen der Ausblühung auf die Gefala a benwand nicht einmal spurenwelse statt.

Die Ausbluhung auf Sortiment 11 läbt unterirdische Blasenbildung nur noch andeutungsweise erkennen. Sie ist aber noch vorhanden. Die Stellen mit mehlartiger Effloreszenz sind in der Hauptsache auf einzelne $\mathrm{Ran}$ ader der Oberfläche beschränkt. Deutlich findet schon ein Herabklettern der Ausblühungskruste an der $G$ efä $\beta$ a u Benwand statt.

Bei den folgenden Sortimenten III, IV, V und VI kennzeichnet sich die Entwicklung der Effloreszenz im fortschreitenden MaBe dadurch, dab sich auf der Sandoberfläche eine mäBig starke durchscheinende Kruste ausbildet, weiche sich durch immer mehr $z u$ nehmende wei $B$ e Punkte auszeichnet und in der gleichen Beschaffenheit immer weiter an der Gefä $b$ a u $B$ enwand her ab erstreckt, je gröber die $S a n d t e i l c h e n$ werden, bis endlich bei Sortiment VI die Kruste sogar noch den Tisch überzieht, worauf das GefäB steht.

Auch bei den Ausblühungserscheinungen, die sich auf dem hier in Rede stehenden Sande einstellten, liegt wiederum das Ergebnis des Ineinandergreifens mehrerer Kapillarvorgänge ohne Zweifel vor.

Es fällt aber sofort auf, daB die Ausblühung viel schwächer auftrat als im vorangegangenen Falle. Eine ungezwungene Erklärung hierfür bietet nach schon gepflogenen Erörterungen die deutliche $B$ eimischung lehmiger Bestandteile zu dem Versuchssand, welche selbstredend im feinsten Sortiment am stärksten vertreten sein muBten, aber auch den Teilen des groben und gröbsten Sandes anhafteten. Die Oberflächengröbe der Gewichtseinheit des Bodens wurde dadurch gegenüber reinem Sande in jedem einzelnen Falle vermehrt und so eine $Z u r u ̈ c k$ haltung der Salzlösung im Innern des Bodens begünstigt. Dab trotzdem Ausblühungen zustande kamen, ist selbstredend die Folge von Verdunstung an der Bodenoberfläche. Wir stehen aber hier vor der Er- 
scheinung, daß die Ausblühung zuerst und zwar erst nach UmfluB einiger Wochen auf dem gröbsten Sortiment bemerkbar wird, hingegen immer später und später auftritt, um je feinkörnigeren Sand es sich handelt. Die Verdunstung war also bei dem hier vorliegenden Versuchsmaterial in den groben Sanden gegenüber den feineren begünstigt. Dies steht im Widerspruch damit, daB die Oberflächengröße des feinen Sandes höher ist als die der groben Sortimente. Allein es bleibt $z$ u bedenken, dab sich in den groben und gröbsten Sortimenten, die hier aus großen, völlig kompakten und $\mathrm{n} i \mathrm{cht}$ a ufs a ug ungsfähigen Quarzbröckchen bestehen, die Verdunstung durch die von oben und auch seitlich etwas nach dem Innern der niederen Bodensäule vordringende Luftzirkulation besonders geltend machen konnte. Auch war die Verdunstung in den feineren Sorti. menten, besonders bei Sortimentl, dadurch gehemmt, daB der Glimmerreicht $u$ m des benützten Sandes die Ausbildung einer förmlichen $\mathrm{Haut}$, einer dünnen Schichte „mineralischer Pappe " ${ }^{34}$ ), an der Oberflä che nach deren starker Durchfeuchtung verursacht. Diese Haut dürfte wohl auch die Ürsache sein, daß die unter verhältnismäßig starker Dampfspannung im Innern der feuchten Sandmasse stehende Lösung die eigentliche Bodenoberfläche wulstig auftreibt und nur an einigen Stellen durchbrechen kann, an welchen auswitterndes Salz als mehlartiger Ueberzug erscheint. Man darf wohl annehmen, dab dies jene Stellen sind, wo die lehmig verkittete Glimmerhaut etwas schwächer ausgebildet ist. Ueberall dort aber, wo dies nicht zutrifft, bewirkt die Dampfspannung eine Faltenbildung mit darunter befindlichen Hohlräumen, die durch Schwindung des Bodens nach völligem Austrocknen kleine Oeffnungen nach oben erhalten.

Gestützt auf diese Annahme, können wir auch Verständnis gewinnen für die Tatsache, daB schon beim Sortiment Il, wo infolge der abnehmenden Teilchengröße der Druck des Wasserdampfes schon nicht mehr so hoch steigen muB, das Durch bre chen der unter Abnahme lehmiger Beimischung an sich schon geschwächten Glimmerhaut nur noch an den Rändern nahe der Gefäbwand, wo die Verdunstung am gröBten ist, einzutreten vermag und die

34) H. Puchner, Vergleichende Untersuchungen über die Kohäreszenz verschiedener Bodenarten (Internationale Mitteilungen für Bodenkunde, 1913, Sonderabdruck, 71). wulstartige Auftreibung der Sandober. fläche vielmals schwächer sich kennzeichnet, um bei den folgenden Sortimenten ganz aufzuhören.

Ferner stehen wir insges a in $t$ bei den Ausblühungen auf den hier benützten Quarzsandsortimenten vor der Erscheinung, dab das $\mathrm{Her}$ abklettern der Effloreszenz an der GefäbauBenwand ganz gleichmäBig mit der Zunahmeder Sortimentsgröbe wächst. Es ist dieser Vorgang nicht, entsprechend dem vorausgegangen betrachteten Dolomitsand, bei den mittleren Sortimenten am stärksten ausgebildet, um dann mit der $\mathrm{Zu}$ nahme der Teilchengröße wieder abzunehmen. Je geringer die Anziehung seitens der immer gröBer werdenden Sandbestandsteile, je geringer deren Aufnahmefähigkeit für die Salalösung und schwächer die Wasserkapazität wird, desto stärker vermag die Glaswand ihre Anziehung auf die Salzlösung auszuüben, ohne dab hier eine störende Nebenwirkung feiner Haarspalten in Innern der Bröckchen, wie bei den groben Teilen des Dolomitsandes, einzutreten vermag. Wir haben also hier das ungetrübte Ergebnis des Kampfes zwischen der Adhäsion der Salzlösung an den Quarzsandteilchen und der Adhäsion der Lösung an der Gefäfwand vor uns.

Hingegen tritt uns auch hier, genau wie beim Dolomitsand, die Erscheinung entgegen, dab in keinem einzigen Falle die Ausblühungen die echte Kristallisationsform des $\mathrm{NaCl}$ erkennen lassen, sondern teils durchscheinende formlose Massen, teils weibes, mehliges pulver darstellen. $\mathrm{DaB}$ auch im vorliegenden Falle dem $\mathrm{NaCl}$ beigemengte fremdartige Bestandteile die Ursache hierfür bilden, erscheint naheliegend. In der Absicht, hierüber Aufklärung zu gewinnen, wurden zunächst wiederum in schon erwähnter Weise sowohl die in den unveränderten wie in den mit $\mathrm{NaCl}$ versetzten Sandsortimenten enthaltenen wasserlöslichen Bestandteile in separaten Porzellanschälchen zu bestimmen versucht.

Die Rückstände der wässerigen Lösungen betrugen bei den $n i c h t$ mit Salx versetzten Sandsortimenten auf je $100 \mathrm{~g}$ Boden (mit $1000 \mathrm{ccm}$ Wasser ausgezogen) die in Tabelle VIII angegebenen Mengen.

Die qualitative Untersuchung der Rückstände ergab, daB in ihnen der Hauptsache nach hochwertig mit Kieselsäure und Eisen gesät* tigte organische Absorptionsverbindung en vorliegen. 
Tabelle VIII.

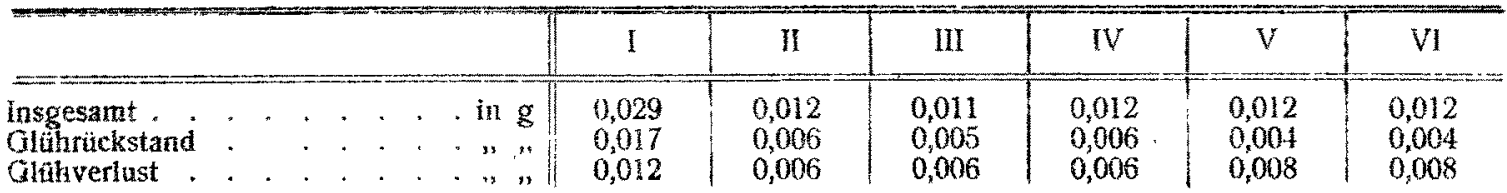

Tabelle IX.

\begin{tabular}{|c|c|c|c|c|c|c|}
\hline & I & II & III & IV & $\mathrm{V}$ & VI \\
\hline 1. Rückstand der wässerigen Lósung des unveranderten & & & & & & \\
\hline Sortimentes & 0,029 & 0,012 & 0,011 & 0,012 & 0,012 & 0,012 \\
\hline 2. Zugesetzte $\mathrm{NaCl}$-Menge. $\cdot$. . & 3,000 & 3,000 & 3,000 & 3,000 & 3,000 & 3,000 \\
\hline 3. Erwartbare Gesamtrückstandsmenge. . . ., & 3,029 & 3,012 & 3,011 & 3,012 & 3,012 & 3,012 \\
\hline $\begin{array}{l}\text { 4. Festgestellte Gesamtrickstandsmenge } \\
\text { 5. Unterschied zwischen festgestellter und erwartbarer }\end{array}$ & $\mathbf{3 , 0 3 7}$ & 2,992 & 2,985 & 3,026 & 3,082 & 3,041 \\
\hline Gesamtrückstandsmenge . . . . . . . " & $-0,008$ & $-0,020$ & $-0,026$ & $1+0,014$ & $+0,020$ & $+0,029$ \\
\hline
\end{tabular}

Unter Festhaltung der in obiger Tabelle VIII wiedergegebenen Zahlen müBten sich bei Hinzurechnung der beim Ausblühungsversuch jeweils auf $100 \mathrm{~g}$ Sand zugesetzten $3,000 \mathrm{~g} \mathrm{NaCl}$ die in der folgenden Tabelle IX unter 3 . angegebenen Rückstandsmengen aus der salzhaltigen Lösung der Sande erwarten lassen, welchen aber die in Wirklichkeit bel vollkommener AussüBung erhaltenen Rückstände letzterer Abstammung, die in Tabelle IX unter 4. anfgefubrt sind, nicht befriedigend entsprechen. Es enthielten die einzelnen Sortimente auf je $100 \mathrm{~g}$ Sand die in Tabelle IX angegebenen Rückstandsmengen.

Es hatte derrinach beim feinsten Sortiment I und bei den drei gröbsten Sortimenten IV, V und VI eine Zunahme, bei den in der Mitte stehenden Sortimenten II und III eine Abnahme der löslichen Bestandteile infolge des Ausblühungsvorganges stattgefunden. Es mag, wie bei Bodenuntersuchungen überhaupt, auch hier unmöglich erscheinen, jeden Einflub von Fehlerquellen auf die Ergebnisse der Untersuchung für ausgeschlossen zu erklären. Aber wenn man anicht so sebr die Höhe der Zahlen, sondern deren Sinn berücksichtigt, gelingt es gleichwohl Verständnis dafür zu gewinnen. Falsch wäre nämlich auch hier, die gewonnenen Resultate als reine Zunahmen und reine Abnahmen zu betrachten, vielmehr sind sie das Endprodukt von einander entgegengesetzt wirkenden Vorgängen, die teils Neubil. dunglöslicher Substanz, teils Verlust an solcher nach sich ziehen. Dies zeigt uns die quantitative Untersuchung der einzelnen Lösungen, deren Befund zu Vergleichen anregt.

So betrug beispielsweise nach Tabelle IX die Gewichtszunahme der festgestellten Gesamt- rückstandsmenge bei Sortiment I insgesamt $0,008 \mathrm{~g}$. Die Bestimmung des Gehaltes an $\mathrm{CaO}$ in dieser Rückstandsmenge ergibt nun durch Analyse $0,032 \mathrm{~g}$. Der Glührückstand der wässerigen Lossung des nicht mit $\mathrm{NaCl}$ versetzten Sortimentes I beträgt nun aber nach Tabelle VIII nur $0,017 \mathrm{~g}$. Demnach war allein schon an $\mathrm{CaO}$ im Rückstand der $\mathrm{NaCl}$-haltigen Lösung um $0,015 \mathrm{~g}$ mehr enthalten gewesen, als die Gesamtmenge des feuerfesten Rückstandes der unveränderten wässerigen Lösung für sich betragen hatte. Und doch war die Gesamtgewichtszunahme infolge des Ausblihhungsvorganges nur zu $0,008 \mathrm{~g}$ festzustellen. Ganz ebenso konnte durch quantitative Analyse bei Sortiment II und III eine Zunahme an $\mathrm{CaO}$ gegenüber dem Glührückstand der wässerigen Lösung des unveränderten Sandes in dem Rückstand der wässerigen Lösung des mit $\mathrm{NaCl}$ versetzten Sandes festgestellt werden. Und trotzdem ergab die Bestimmung der Gesamtrückstandsmenge für beide Sortimente Abnahmen, wie Tabelle IX dartut.

Es fanden also während der Entwicklung der Ausblühungen Zuwachsvorgänge und Verlustvorgänge in bezug auf wasserlösliche Substanz statt. Infolge des lehmigen Beischlages mit schwachem Kalkgehalt, der dem hier vorliegenden Sande eigen war, kann uns bei den drei feinsten Sortimenten das Anwachsen des Gehaltes an $\mathrm{CaO}$ durch Umsetzungen mit $\mathrm{NaCl}$ nicht befremden. Aber auch die auf Verringerung löslicher Substanz hinarbeitenden Vorgänge sind nicht schwer zu bezeichnen. Die Zersetzung von $\mathrm{NaCl}$ und Karbonaten durch humose Kolloide, welche in geringen Mengen und vielleicht recht wirksamer Form auch in diesem Sande vorhanden waren, erscheint jedenfalls möglich, 
und die starken blasigen Auftreibungen an der Oberfläche von Sortiment I lassen sich unter Annahme spurenweiser $\mathrm{HCl}$ - und $\mathrm{CO}_{2}$-Entwicklung im Boden noch leichter erklären als lediglich durch die Wirkung von Wasserdampf. Dazu kommen dann noch die möglichen Ausflockungen von kolloid gelöst gewesenen Eisenoxydhydrat, Tonerdehydrat und Kieselsätrehydrat sowie organischen Kolloiden durch die starke $\mathrm{NaCl}$ Lösung.

Durch diese und vielleicht noch andere nicht näher bezeichnete Vorgänge läbt sich auch eine Erklärung für das typische Bild der Ausblühungen auf den einzelnen Sortimenten des hier vorliegenden Bodens geben. Von den blasigen Auftreibungen auf Sortiment I wurde schon ge sprochen. Die gleichzeitig damit auftretende mehlartige Effloreszenz an den Rändern des Bodenkuchens (Abb. 12) und zwischen den Blasen lieb sich in einfacher Weise als durch beigemengte Hydrate verursacht erkennen. Denn wurde eine geringe Menge dieses Mehls auf einem Uhrglas in etlichen Wassertropfen autgelöst und deren Verdunstung abgewartet, so schieden sich innerhalb einer am Uhrglas hattenden Trübung, in der $\mathrm{SiO}_{2}, \mathrm{Pe}_{2} \mathrm{O}_{3}$ and $\mathrm{C}_{2} \mathrm{O}$ ermittelt werden konnten, tadellose $\mathrm{NaCl} \cdot \mathrm{Kri}-$ ställchen und daneben einzelne feinste Nadeln $\mathrm{ab}$, welche alkalische Reaktion zeigten. $\mathrm{CaO}$ nachweisen lieBen und auf Grund der gegebenen Bedingungen sich vielleicht als identisch oder verwandt mit dem basischen $\mathrm{Salz} \mathrm{Cl} C \mathrm{Ca} . \mathrm{O} . \mathrm{Ca}(\mathrm{OH})$ $+7 \mathrm{H}_{2} \mathrm{O}$ vermuten lassen $\left.{ }^{35}\right)_{\text {, das man künstlich }}$ durch Kochen von Chlorkalziumlösung mit Kalziumoxydhydrat erhält. Hatten die in der Trübung des Uhrglases enthaltenen Hydroxyde in wässeriger kolloider Lösung die Ausbildung regelrechter $\mathrm{NaCl}$-Kristalle zu unterdrücken vermocht, so waren sie dazu nach vollzogever Austrocknung im irreversiblen Zustande nicht mehr fähig. Denn Eisenoxydhydrat, Kieselsäure usw. sind Kolloide, die durch das Trocknen dauernde Veränderung erleiden.

Waren ferner in der durch die Glimmerhaut der. Sandoberfläche stark beschränkten und nur stellenweise hervorbrechenden Ausbluhung auf dem feinsten Sortiment die eben erwähnten Beimengen imstande, völlig den Eindruck einer mehligen, allerdings festen Masse hervorzurufen, so konnte in den aus den groben Sortimenten usgehindert hervorbrechenden Salzmengen durch die aus noch anlaftenden feinen, lehmigen Teil-

35) Vgl. Roscoe und Schorlemmer, Ausfithrliches Lehrbuch der Chemie (Braunsehweig 1307), 463. chen gebildeten Hydrate nur noch eine Trübung oder stellenweise auftretende weibe Punktierung, die auf Ausflockung deutet, hervorgerufen werden, allerdings mit der Nebenwirkung, daB auch hier die echte Kristallform des $\mathrm{NaCl}$ zur Unterdrückung kam.

Auffallend ist, daß bei den drei gröbaten Sortimenten IV, V und VI deutlich und zwar in der angegebenen Reihenfolge mit wechselnder Intensilät eine Zunahme der feststellbaren gegenüber der erwartbaren Gesamtrückstandsmenge zu verzeichnen war. Die auf Verlust an löslicher Substanz hinarbeitenden Vorgänge muBten demnach zugunsten der entgegengesetzt wirkenden Vorgänge eine Einschränkung erfahren haben. Dies kann damit in Zusammenhang gebracht werden, daB in den zunehmend größer werdenden Teilen der gröberen Sortimente von Sendböden die beigemischte Menge darin noch enthaltener unzersetzter Silikate wächst, wie Verf. ${ }^{36}$ ) bereits früher nachgewiesen bat und $\mathrm{NaCl}$-Lösung auberordentlich geeignet zu Umsetzungen mit Silikaten verschiedener Art ist.

\section{Ausblühungen}

auf scbwach eisenschüssigem, humo sen Quarzsand.

Der verwendete Quarzsand von gelblichbrauner bis schwach rötlicher Farbe wurde am 13. Oktober 1911 in gleicher Weise wie die vorausgegangenen Sande behufs Entwicklung von Ausbluhungen aufgestellt. Die einzelnen Sortimente verhielten sich folgendermaken:

\begin{tabular}{|c|c|c|}
\hline $\begin{array}{l}\text { Beginn der } \\
\text { Ausblithung. }\end{array}$ & & $\begin{array}{l}\text { Beginn der } \\
\text { Ausblühung. }\end{array}$ \\
\hline 24. Oktober & V & 19. Oktober \\
\hline 23. Oktober & VI & 18. Oktobet \\
\hline $\begin{array}{l}\text { 22. Oktober } \\
\text { 2i. Oktober }\end{array}$ & VII & 16. Oktober \\
\hline
\end{tabular}

Am 10. November waren die Ausbithungen auf allen Sandsortimenten sichtlich vollendet. Das in Abb. 13 dargestellte Bild, welches sie boten, war untereinander aber sehr verschieden. Es zeigte sich nämlich auf Sortiment:

Tabelle X.
I $1,5 \mathrm{~cm}$ Höhe, kein Uebergreifen der Ausblüh. ung auf đie GefäBaußenwand.
Rasen feinster, durchsichtiger Salznadein von
86) 'H. Puchner, Ueber die Verteilung von Nahr. stoffen in den verschieden feinen Bestandteilen des Bodens (Die landwirtschaftichen Versuchs-Stationen. 1907, 463). 


\begin{tabular}{|c|c|}
\hline II & $\begin{array}{c}\text { Rasen ieinster, durchsichtiger Salznadeln von } \\
0,2-0,3 \mathrm{~cm} \text { Hohe, kein Uebergreifen der Aus- } \\
\text { blühung auf die Gefaßaußenwand. }\end{array}$ \\
\hline III & $\begin{array}{l}\text { Rasen feiner, durchsichtiger Salznadein von } \\
0,1 \mathrm{~cm} \text { Hohe, schwaches Uebergreifen der Aus- } \\
\text { blihhung auf die Gefäßaußenwand. }\end{array}$ \\
\hline IV & $\begin{array}{c}\text { Mit Salznadeln vermischte Kruste von } 0,05 \mathrm{~cm} \\
\text { Dicke, verstärktes Uebergreifen der Ausblithung } \\
\text { auf die Gefäßaußenwand. }\end{array}$ \\
\hline $\mathrm{V}$ & $\begin{array}{c}\text { Gleichmäßige Salzkruste auf der ganzen Sand- } \\
\text { oberfläche, starkes Uebergreifen der Ausblïh- } \\
\text { ung auf die Gefäßaußenwand. }\end{array}$ \\
\hline VI & $\begin{array}{l}\text { Gleichmäßige Salzkruste auf der ganzen Sand- } \\
\text { oberfláche, schwache Andeutung tesseraler Kri- } \\
\text { stallflächen, starkes Uebergreifen der Ausblüh- } \\
\text { ung auf die Gefäßaußenwand. }\end{array}$ \\
\hline VII & $\begin{array}{c}\text { Gleichmäßiger, dünner, glänzender Salzüberzug } \\
\text { mit deutlichen tesseralen Kristallflächen, Her- } \\
\text { abreichen der Ausblühung an der Gefäßaußen- } \\
\text { wand bis auf die Unterlage und noch uber diese } \\
\text { hinweg. }\end{array}$ \\
\hline $\begin{array}{l}\text { daB } \\
\text { seits } \\
\text { seits } \\
\text { ung } \\
\text { Sor } \\
\text { dü } 1 \\
\text { de } \\
\text { NaC } \\
\text { auf } \\
\text { stau } \\
\text { sic } \\
\text { nad } \\
\text { fläcl } \\
\text { bem } \\
\text { und } \\
\text { Sor } \\
\text { ein } \\
\text { Gie } \\
\text { a u f }\end{array}$ & 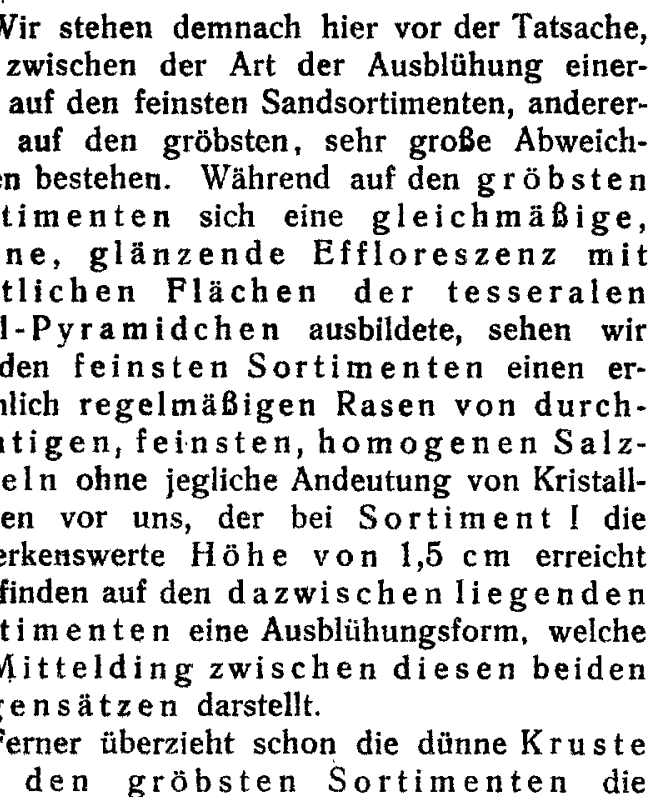 \\
\hline
\end{tabular}

Oberfläche nicht vollkommen lückenlos, sondern läBt deutlich erkennen. daß sie an den Stellen der größten Entfernungen zwischen den benachbarten Teilchen unterbrochen und nur an den Berührungsstellen derselben zusammenbängend ist. Diese Neigung zur Auflösung der Gesamteffloreszenz in lauter einzelne selbständige Teile verstärkt sich mit Zunahme der Feinheit des

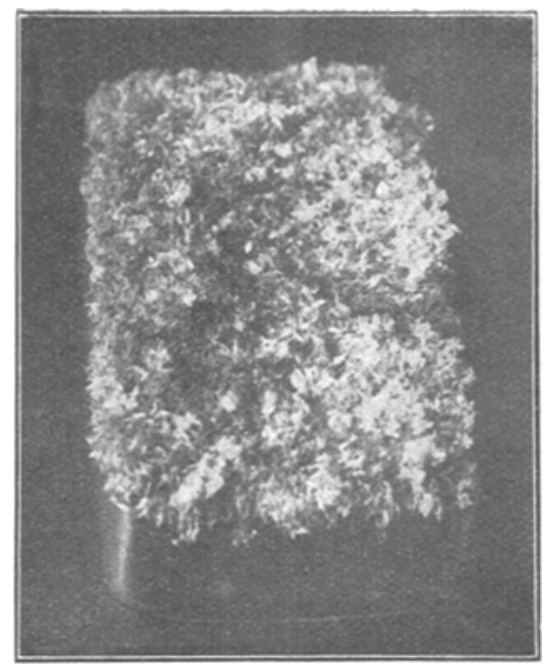

Abb. 14.

Ausbluhungen auf Sortiment I von stark humosem eisenschüssigen Quarzsand mit 3 Gew.-Proz. Na Cl.

Sortimentes aber immer mehr, bis schließlich sogar die dünnen Nadeln auf dem feinsten Quarzsand I ganz deutlich schon mit freiem Auge an der Stelle, wo sie aus dem Boden herauswachsen, Abstände von $0,1-0,2 \mathrm{~mm}$ und darüber erkennen lassen.

Und noch eine weitere Erscheinung muB festgestellt werden. Je deutlicher sich in der Effloreszenz die Zerteilung in einzelne Nadeln mit zunehmender Feinheit des Sandsortiments

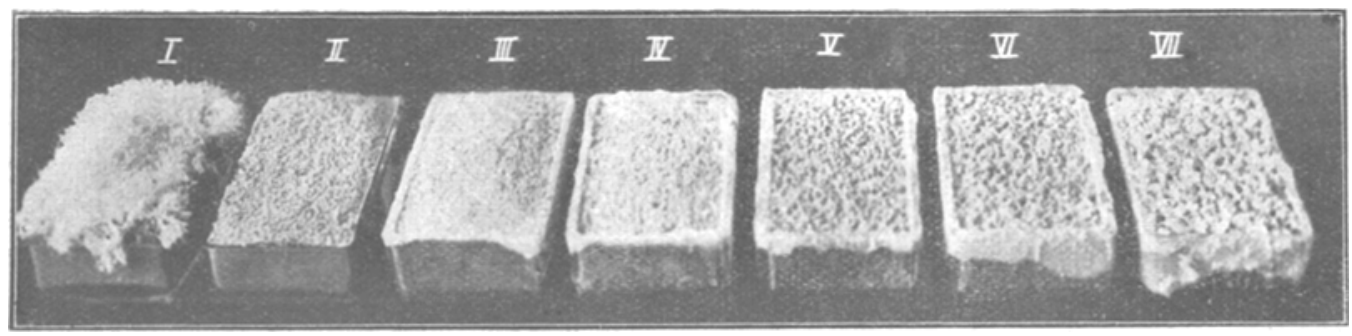

Abb. 13.

Ausblibhungen auf schwach eísenschüssigem, humosen Quarzsand mit 3 Gew.-Proz. Na Cl. 
einstellt, desto weniger Neigung bekundet sie, an der GefäBaubenwand herabzuklettern, so dab bei den feinsten $Q$ uarzsanden 1 und II auch nicht einmal spurenweise ein Uebergreifen der a usgeblühten Salzmenge auf die Gefäbränder stattfindet, während sich das Herabklettern der Ausblühung an der GefäBaußenwand bei Sortiment III schon deutlich einstellt und fortschreitend bis zu Sortiment VII sich soverstärkt, daß bei diesem die Effloreszenz stellenweise schon die Unterlage des Ausblühungsgefäßes überzi e ht.

Die zweifellos auch hier vorliegenden Ergebnisse von Kapillarvorgängen äubern sich demnach teilweise in wesentlich anderen Bildern als bei den bisher betrachteten Sanden. Zwar macht sich, wie beim schwach mergeligen, glimmerreichen Quarzsand der vorhergegangenen Sortimentsreihe, auch hier die Ausblühung $z$ uerst auf dem gröbsten Sortiment bemerkbar, aber auf diesem ist die entstehende Kruste nicht formlos, sondern weist stark glänzende, grobe Kristallflächen des $\mathrm{NaCl}$ auf. Und bereits ganz kurze Zeit darauf bildet sich fortschreitend bei den $z u$ nehmend feineren Sortimenten eben* falls die Effloreszenz heraus, deren Wachstum dann $u m$ so rascher vonstatten geht und zum AbschluB kommt, je feinkörniger das
Sortiment ist. Am überraschendsten wirkt aber das beim feinsten Sortiment I mit einer gewissen Plötzlichkeit sich betätigende Hervorbrechen von in kurzer Zeit $1,5 \mathrm{~cm}$ lang werdenden $S$ al znädelchen, das gewissermaBen an das Aufgehen einer leicht keimenden Sämerei erinnert. Alles deutet darauf hin, daß, ähnlich wie beim vorigen Sandmaterial die Verdunstung bei den groben Sortimenten begünstigt, bei den feineren und ganz besonders den feinsten Sortimenten gehemmt war. Wahrend sie aber beim feinsten Sortiment des vorausgehend betrachteten mergelig-glimmerigen Sandes infolge des Vorhandenseins der Glimmerhaut an der Oberfläche so gut wie dauernd und fast vollkommen unterdrückt war, hat dieser Zustand hier nur bis zu einem gewissen Grade anzudauern vermocht. Ist dieser erreicht, dann wird die Oberfläche von der Ausblühung durchbrochen und ein Wald von Nadeln erhebt sich.

Eine Reihe besonderer Erscheinungen drängt demnach wieder nach Aufklärung. Dieser näher $z u$ kommen, wurden zunächst wiederum die Rückstände der wässerigen Lösungen der nicht mit Salz versetzten Sandsortimente in der schon erwähnten Weise festgestellt. Es waren enthalten in $100 \mathrm{~g}$ die in Tabelle XI angegebenen Rückstandsmengen.

Tabelle XI.

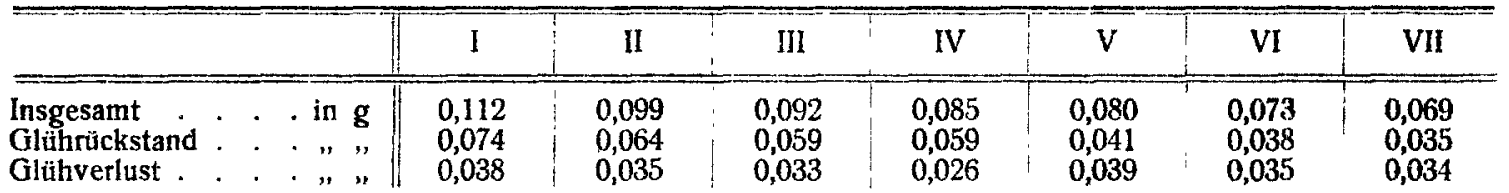

Tabelle Xll.

\begin{tabular}{|c|c|c|c|c|c|c|c|}
\hline & I & II & III & IV & V & VI & VIl \\
\hline $\begin{array}{l}\text { 1. Rückstand der wässerigen Lösung des unveränderten } \\
\text { Sortimentes } \\
\text { 2. Zugesetzte } \mathrm{NaCl} \text {-Menge } \\
\text { 3. Erwartbare Gesamtrickstandsmenge . } \\
\text { 4. Festgestellte Gesamtrückstandsmenge } \\
\text { 5. Ueberschuß der festgestellten gegenüber der erwart-" } \\
\text { baren Gesamtrückstandsmenge. }\end{array}$ & $\begin{array}{l}0,112 \\
3,000 \\
3,112 \\
\mathbf{3 , 4 0 1} \\
\mathbf{0 , 2 8 9}\end{array}$ & $\begin{array}{l}0,099 \\
3,000 \\
3,099 \\
\mathbf{3 , 3 0 4} \\
\mathbf{0 , 2 0 5}\end{array}$ & $\begin{array}{l}0,092 \\
3,000 \\
3,092 \\
\mathbf{3 , 2 2 7} \\
\mathbf{0 , 1 3 5}\end{array}$ & $\begin{array}{l}0,085 \\
3,000 \\
3,085 \\
\mathbf{3 , 1 7 4} \\
\mathbf{0 , 0 8 9}\end{array}$ & $\begin{array}{l}0,080 \\
3,000 \\
3,080 \\
3,142 \\
0,062\end{array}$ & $\begin{array}{l}0,073 \\
3,000 \\
3,073 \\
\mathbf{3 , 1 6 4} \\
\mathbf{0 , 0 9 1}\end{array}$ & $\begin{array}{l}0,069 \\
3,000 \\
3,069 \\
\mathbf{3}, 180\end{array}$ \\
\hline
\end{tabular}

Die qualitative Untersuchung der Rückstände ergab, dab in ihnen der Hauptsache nach absorptiv ungesättigte organische hum ose Verbindungen mit angelagertem $\mathrm{Fe}_{2} \mathrm{O}_{3}$, $\mathrm{CaO}, \mathrm{MgO}$ und $\mathrm{SiO}_{2}$ vorliegen.

Unter Berücksichtigung der in obiger Tabelle XI enthaltenen Zahlen würden sich bei Hinzurechnung der beim Ausblühungsversuch jeweils auf $100 \mathrm{~g}$ Sand zugesetzten $3,000 \mathrm{~g}$ $\mathrm{NaCl}$ die in der folgenden Tabelle XII unter 3. angegebenen $R$ ü ckstandsmengen aus der salzhaltigen Lösung der Sande erwarten lassen, welchen aber in Wirklichkeit bei vollkommener AussüBung erhaltenen Rückstände letzterer Abstammung, die in Tabelle XII unter 4. aufgeführt sind, keineswegs entsprechen. $E_{3}$ 
ergaben sich in den einzelnen Sortimenten auf je $100 \mathrm{~g}$ Sand die in Tabelle XII angegebenen Rückstandsmengen.

Es war also durch den $Z$ us at $Z$ von $\mathrm{NaCl}$ in allen Sortimenten eine Zunahme der löslichen Bestandteile eingetreten. Um hierfür Verständnis zu gewinnen, müssen wir uns vor allem wieder über die zugrunde liegenden Verhältnisse Rechenschaft zu geben suchen. Die durch die Versetzung mit Salz in Lösung gegangenen Verbindungen können nur aus Bestandteilen des Bodens herrühren, die in dessen salzfreiem Zustand schwer löslich oder wasserunlöslich waren. In dieser Beziehung sei zunächst auf jene Verbindungen hingewiesen, die in einer $\mathrm{NaCl}$-Lösung an sich ein höheres Lösungsvermögen besitzen als im reinen Wasser. So wird Gips, der im vorliegenden Sandboden in mäBigen Mengen nachweisbar war, fünfmal so stark gelöst als sonst. Ebenso wirkt $\mathrm{NaCl}$ lösend auf Kalk, Magnesia und Phosphorsaure, die in geringen Mengen ebenfalls zugegen waren, wie durch qualitative Untersuchung der Feinerde festgestellt werden konnte. Von noch größerer Wirkung aber dürfte im vorliegenden Falle die Umsetzung der $\mathrm{Na} \mathrm{Cl-Lösung} \mathrm{mit} \mathrm{reichlicher} \mathrm{vorhandenen} \mathrm{Boden-}$ bestandteilen $z u$ veranschlagen sein. Es sind dies bekanntlich im vorliegenden Falle Humate und Silikate. Die humosen Beimengungen, deren Gegenwart schon der Glühverlust der Rückstände der wässerigen Lösungen unter Schwärzung verriet, waren durch einfache mechanische Ueberprüfung erst recht reichlich erkennbar. Und was die Silikate betrifft, so können sie in fast jedem Quarzsandboden als Beimengung zu den Kieselsäurekörnchen 'nachgewiesen werden. Verf. ${ }^{37}$ ) hat.festgestellt, daf namentlich die feineren und feinsten Sortimente jene organischen Verbindungen enthalten, welche man früher ausschlieBlich als Humate betrachtete, jetzt aber auch als mineralorganische Kolloidkomplexe anspricht, worin Kalk, Tonerde, Eisen, Mangan usw. angelagert sind und hat nachgewiesen, dab die gröberen Sortimente merkliche Anteile von Silikaten aufweisen. Es ist ferner durch wiederholte Untersuchungen ${ }^{38}$ )

37) H. Puchner, Ueber die Verteilung von Nahrstoffen in den versclieden fejnen Bestandieilen des Bodens (Die landwirtschaftlichen Versuchsstationen 1907, 463). - Vergleichende Untersuchungen uber die Kohäreszenz verschiedener Bodenarten (Internationale Mittellungen fuir Bodenkunde 1913).

- Eich horn, Einige Beitrüge zu den Absorptionserscheinungen in der Ackererde (Landw. Jahrbücher erhärtet, daB sîch $\mathrm{NaCl}-\mathrm{L}$ ösung mit organischen Kolloidkompiexen und mit bestimmten Silikaten umsetzt.

In den hierdurch angedeuteten Umsetzungen haben wir nun die Ursache dafür $z u$ erblicken, daß einmal ganz allgemein in sämtlichen Fällen der Ausblühung eine Vermehrung des Rückstandes der wässerigen Lösung des $\mathrm{NaCl}$ versetzten $Q$ uarzandes gegenüber dem salzfreien Boden eintrat. Andererseits geben uns obige Betrachtungen aber auch eine Erklärung für die aus Tabelle XII sprechende Beziehung, daß die mittleren Sortimente die schwächste Vermehrung an wasserlöslichen Substanzen a ufweisen, während sich von hier aus ein Anwàchsen der Rückstände sowobl mit Zunahme der Sortimentsgröße wie auch ganz besonders mit fortschreitender Feinheit des Sortimentes erkennen läBt. Denn die zu Umsetzungen mit $\mathrm{NaCl}$ geneigten Humate und Silikate sind in den mittleren Sortimenten am schwächsten vertreten, während die Gegenwart der Silikate in den groben, am wenigsten zersetzten Kornern des gröbsten Sortimentes am reichlichsten gegeben ist und andererseits das feinste Sortiment wiederum die bedeutendsten Mengen an humosen Bestandteilen enthält. Dabei soll nicht unbetont bleiben, daß für dieses feinste humusreiche Sortiment und vielleicht auch noch das nächststehende desselben usw. die Zunahme an löslicher Substanz im Rückstand der wässerigen Lösung wohl noch höher eingeschätzt werden darf, als es die Zahlen der Tabelle XII angeben, denn wir wissen ja, dab durch die humosen Kolloide auch $\mathrm{NaCl}$ unter $\mathrm{HCl}$-Abscheidung zerlegt und daß wasserlösliches ursprüngliches Kolloid des unveränderten Bodens durch die $\mathrm{NaCl}$-Lösung ausgeflockt werden kann, die Vermehrung löslicher Salze also auch diesen Verlust noch zu decken hat, bevor sie zahlenmäßig in Erscheinung $\mathrm{zu}$ treten vermag. Tatsächlich war beim Eindampfen der wässerigen Lösungen der Ausblühungen besonders von Sortiment I und II schwaches Aufperlen $z u$ beobachten und ausgesprochen blatternarbenartige Beschaffenheit des Rückstandes, von entweichenden Gasblasen vielleicht verursacht, festzustellen, ebenso wie

1875, 21 ff.). H. Puch ner, Untersuchungen iber den Transport der loslichen Salze bei der Wasserbewegung im Boden (Forschungen auf dem Gebiete der Agrikulturphysik 18, Heft $1-2$. 
die schon weiter oben wiederhuit erörterte Trübung in Waschwasser beim Aussüben des Bodens auftrat.

Auf solchen Grundlagen weiter bauend, können wir auch eine Erklärung für die verschiedenartige Bildungsform der Ausblühungen einerseits auf den gröbsten, andererseits den feinsten Sortimenten des vorliegenden Quarzsandes versuchen.

Dab zunächst in der Ausblübung auf dem gröbsten Sortiment VIl trotz derfestgestellten Beimengung anderer Bestandteile zum $\mathrm{NaCl}$ keine Beeinflussung der Kristallform desselben einzutreten vermochte, kann nach obigem nur so gedeutet werden, daß die Verunreinigungen, welche nach Art der beschriebenen Vorgänge in den Ausblühungen der gröbsten Sortimente vorliegen mußten, von nach dieser Richtung wirkungsloser mineralischer Natur waren und hauptsächlich von der Umsetzung zwischen (kalkfreien) Silikaten und $\mathrm{NaCl}$ herrühren mochten. Daß die Qualität und nicht die Menge der Verunreinigungen ausschlaggebend ist, könnte daraus gefolgert werden, daB in den minder groben Sortimenten VI, V, IV weniger Gewichtszuwachs in der Aushlühung festzustellen war als in Sortiment VII und doch auf diesen Sortimenten die Ausblühung schon nicht mehr in der eigentlichen Kristallform des $\mathrm{NaCl}$ zustande kam.

Noch viel reichlicher ist in zunehmender Reihenfolge der Ueberschul über die erwartbare Salzmenge in den Ausblühungen auf den fe in sten Sortimenten III, II, I. Dies kann in Beziehung zu der oben erwähnten Tatsache gebracht werden, daß den Sortimenten mit zunehmender Feinheit statt silikatischer Einschläge immer reichlicher humose Körper und den Lösungen, woraus die Ausblühungen entstehen, dadurch zunehmende Mengen organischer Iöslicher Substanz beigemengt sind. Das beobachtbare, damit verbundene Zurücktreten der tesseralen Kristallform des $\mathrm{NaCl}$ wird aber gleichzeitig immer stärker durch ausgesprochenste Nadelform der Ausblühung ersetzt.

Die beim Eindampfen der wässerigen Lösungen dor Ausblühungen feststellbaren Erscheinungen zeigen nun deutlich, daB die organische Beimengung darin bei den feinsten Sortimenten vollkommen viele jener Eigenschaften aufweist, welche den als Gelatine und arabischer Gummi bezeichneten Kolloiden zukommt. Die charakteristische Nadelform der Ausblühung wird dadurch verständlich.
Die durch den gelatinösen Einschlag ihrer Kristallisationsfahigkeit be* raubte $z$ ähflïssige $\mathrm{NaCl}-1$ ösung wird durch die Dampfspannung bei. der Volum verminderung des sich zusammenziehenden, austrocknenden Bodens in den engen Zwischenräumen zwischen den benachbarten kompakten Sandteilchen langsam wie eine Fontäne emporgepreBt und. $z$ war um so höher, je geringer der mögliche Querschnitt der Nadeln und jo stärker der nach aufwärts wirkende Druck ist, am höchsten demnach bei dem feinston Sortiment. Und während dieses durch kapillaren Nachschub begünstigten Vorganges tritt infolge der starken Verdunstung nach allen Seiten Erstarrung zu Nadeln ein. Dem naheliegenden Einwand, warum diese Nadelbildung dann auch nicht bei anderen Sanden mit humoser Beimengung eintritt, beispieisweise beim Dolomitsand oder dem mergelig-glimmerigen Quarzsand, die weiter oben behandeli wurden, kann dadurch begegnet werden, dab nur die völlig kompakten, für die Salzlösung undurchdringlichen Teilchen des Quarzsandes ohne glimmerige Beimengung die Salzlösung zwischen sich emporpressen können, während eine Glimmerhaut an der Oberfläche diesen Vorgang ganz verhindert und die poröse Beschaffenheit der Dolomitteilchen bedingt, daf Lösung nicht nur in den Zwischenräumen der Dolomitteilchen, sondern auch auf diesen selbst Ausblühung veranlaßt, also deckenartige Form der Ausblühung bedingt, der Nadeln nur ganz vereinzelt beigemengt sind (vgl. Beschreibung dieser Salzplatte).

Die rein nadelartige Form der $\mathrm{NaCl}$ Ausblühung ist in Abb. 13 bei den feinsten Sortimenten $I$ und II am vollkommensten ausgeprägt vorzuíinden. Es wachsen nämlich die an ihren oberen Enden frei in die Luft ragenden Salznadeln durchaus senkrecht in die Höhe. Nur fallen sie nach Erreichung einer gewissen Länge infolge von Erschütterungen oder Luftbewegungen leicht seitlich um (Sortiment $I$ in $A b b: 13)$ und erinnern dann an lagernde Getreidefrucht.

Enthält der gleiche Sand aber sehr reichlich feinere, doch immerhin makroskopisch schon erkennbare humose Teilchen beigemengt, so stellt sich das in Abb. 14 für Sortiment I wiedergegebene, etwas abgeänderte Bild der nadelförmigen Ausblühung ein. Die auf der Sandoberfläche verstreuten Humusteilchen verhindern nämlich stellenweise die von unten hervorbrechenden Salznadeln, an der Spitze 
weiterzuwachsen oder beeinträchtigen wenigstens diesen Vorgang etwas. Einzelne Nadeln bleiben dadurch im Längenwachstum zurück. Auch tritt an Stellen, wo sich schon gebildeten Salznadeln seitlich Humusteilchen anheften, die mit hochgehoben wurden, eine Betätigung des kapillaren Druckes nach seitwärts ein. Es entstehen so vereinzelt strauch- und moosartig verästelte $\mathrm{Par}$ tien in der Ausblühung. ${ }^{*}$ Viele schon entstandene Salznadeln sind auch an ihrem oberen Ende gruppenweise in gröberer Zahl durch derartige Anhängsel verklebt, ähnlich einer durch gemeinsames Kapitäl verbundenen Mehrzahl von Säulen. In diesen einzelnen Salznadeln herrscht aber auberdem nicht ganz gleiches Längenwachstum, es treten also gegenseitige Spannungswiderstände im Wachstum der einzelnen, oben fest verbundenen Nädelchen ein. Die Folge hiervon sind Biegungen einzelner Nadeln, andere werden durch den Zug der benachbarten im unteren, dem Boden nahen Teil verdünnt, gedehnt, ja wieder einige reiben auf diese Weise ibberhaupt von der Bodenoberfläche $a b$ und hängen an den Humusteilchen, die den Gipfel der benachbarten Salznadeln krönen, nicht nur senkrecht herab, sondern ragen auch infolge von Spannungsunterschieden innerhalb ihrer Längenerstreckung nach den verschiedensten Richtungen seitwärts und abwärts, wie Luftwurzeln einer Pflanze, hinaus. Zu Beginn der Ausblühung treten in solchen Fällen moos-, baum-, strauchartige Effloreszenzen von ganz geringer Höhe vereinzelt auch dadurch auf, daß sich poröse, an der Salzoberfläche liegende Humusteilchen mit der kolloidhaltigen Salzlösung durchtränken und diese dann, den verschiedenen Richtungen der Porengänge folgend, nach allen Seiten aus den humosen Oberflächenteilchen hervorbricht und erstarrt. Die reichlichen Humusteilchen sind auch die Ursache, daß in diesem Falle die Ausblühung nicht rein weib, wie in $A b b .13$, sondern mit braunen und schwarzen Punkten und Flecken untermischt erscheint. Alle diese Vorgănge lassen sich in der durch Abb. 14 dargestellten Ausblühung bei näherer Betrachtung deutlich erkennen.

Daß ein organisches Kolloid von ganz bestimmter Artung in dem hier vorliegenden Quarzsand diese auffallenden Aenderingen in der Kristallform des ausblühenden $\mathrm{NaCl}$ hervorruft, erscheint schon nach allen bisher gepflogenen Erörterungen wenig zweifelhaft. Verf. suchte aber auch weitere Beweise hierfür zu erbringen. $\mathrm{Zu}$ diesem $\mathrm{Zwecke}$ wurde die Hälfte einer bestimmten Menge feinsten Sortimentes des gleichen
Quarzsandes mehrwöchentlich mit konzentrierter $\mathrm{H}_{2} \mathrm{SO}_{4}$ gebeizt, un die organische Substanz zu zerstören, dann wochenlang durch Dekantieren aus gewaschen und getrocknet. Mit dem so vorbereiteten Quarzsand wurde nun in der gleichen Weise wie mit der unbehandelt gebliebenen Hälfte der Ausblühungsversuch abermals durchgeführt. Die Ausblühung auf dem ungebeizten Sandsortiment I ergab wieder das gleiche Bild langer Nadeln, wie es bereits in Abb. 13 dargestellt ist. Hingegen entstand auf dem gebeizt gewesenen Sandsortiment I eine Ausblühung, deren Ansicht aus Abb. 15 entnehmbar ist. An Stelle. jeder einzelnen Nadel zeigte sich ein Häufchen

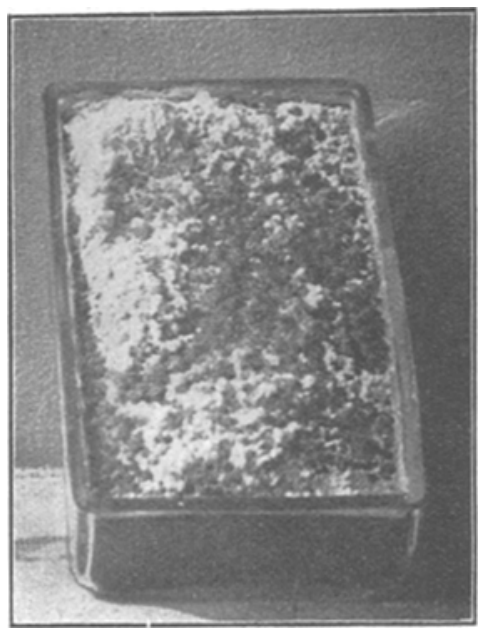

Abb. 15

Mit konzentrierter $\mathrm{H}_{2} \mathrm{SO}_{4}$ gebeizter humoser Quarzsand (Sortiment I) mit 3 Gew.-Proz. NaCl.

schneeigen Pulvers, woraus sich die Gesamtausblühung zu einer locker gelagerten, blendend wei ben $M$ asse überhöhte, welche stellenweise durch beigemengte kohlige Substanz aus dem zerstörten Humus schwarz gesprenkelt erschien. Die qualitative Untersuchung ergab, daB sich das weiße $\mathrm{NaCl}$-Pulver beim Glühen nicht schwärzte, hingegen reichlich $\mathrm{Kiesel-}$ s äu re beigemengt enthielt, von der wir wissen, dab sie eine beim Austrocknen zerreibliche, lockere Modifikation einer kolloiden Substanz anzunehmen vermag. Das Hineingeraten kolloider Kieselsäure in die $\mathrm{NaCl}$-Lösung erscheint aber leicht verständlich, denn durch konzentrierte Säuren werden die den Quarzsandkörnchen beigemengten Silikate nach Art der Zeolithe und jene, worin eine starke Base überwiegt, unter Abscheidung von gallertartiger Kieselsäure 
aufgeschlossen, die nur äußerst langsam wasserlöslich ist and daher im vorliegenden Falle nicht vollkommen weggewaschen werden konnte. Zusammengefaßt darf also das Ergebnis dieses Ausblühungsversuches sicher als weiterer Beitrag zum Beweis dafür gelten, daß nur das in der $\mathrm{NaCl}$-Lösung des ungebeizten feinsten Sortimentes des humosen Quarzsandes enthaltene organische $\mathrm{Humuskolloid}$ die Ursache der Nadelform der Ausblühung ist. Und diese Einwirkung konnte um so ungeschwächter zum Ausdruck kommen, weil die kompakten undurchdringbaren Quarzteilchen die Lösung vollkommen in den Bodenporen zwischen sich emporzupressen vermögen, ganz abweichend vom weiter oben behandelten porösen Dolomitsand und vom mergelig-glimmerigen Sand mit seiner schwach lehmigen Beimischung und der Glimmerhaut an der Oberfläche.

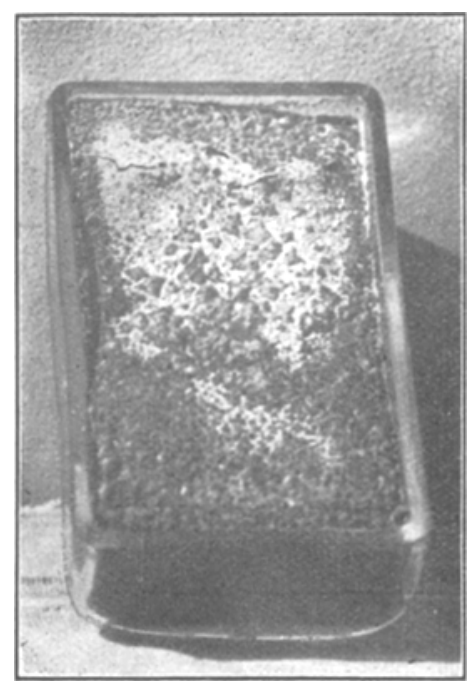

Abb. 16

Aus "Naßgallen" slammender humoser Quarzsand (Sortiment I) mit 3 Gew.-Proz. Na Cl.

$\mathrm{DaB}$ die Zerstörung eines besonderen löslichen humosen Kolloids die Fähigkeit zur Nadelbildung in der Ausblühung beseitigt, konnte Verf. aber noch durch eine andere Beobachtung bestätigt finden. Wurde derselbe Sand, der Nadeln von $\mathrm{NaCl}$ auszuwittern vermochte, solchen Stellen ("NaBgallen") des Bodens entnommen, wo die organischen Schutzkolloide, welche Eisenverbindungen in Lösung erhalten, durch Eisenbakterien abgebaut waren ${ }^{39}$ ) und dadurch das greller gefärbte Giel des kolloiden Eisenoxydhydrates als ausgeschie- dene Bodenbeimengung vorlag, so besaßen die eingeleiteten Ausblühungen schon auf dem feinsten Sortiment ebenfalls $k$ e in e Fähigke it $\mathrm{zur} \mathrm{Nadelbildung.} \mathrm{Vielmehr} \mathrm{wiesen} \mathrm{sie}$ die in Abb. 16 dargestellte tropfsteinartige Ausbildung auf, gekennzeichnet durch Aneinanderreihung unzähliger, wohl den einzelnen Bodenporen entsprechenden Wärzchen, die an ihrer Oberfläche deutlich eine Haut mit den echten Kristallformen des $\mathrm{NaCl}$ erkennen lieben.-

Endlich sei als letzter Beweis für den $\mathrm{Zu}$ sammenhang zwischen Gehalt des Bodens an humosen Hydrosolen und nadelförmiger Ausbildung der $\mathrm{NaCl}$ - Effloreszenz ein Ausblühungsversuch erwähnt, den Verf. mit völlig humusfreiem Seesand, wie ihn die Brandung auswirft, durchführte. Der mit 3 Gew.-Proz. $\mathrm{NaCl}$ versetzte Sand lieferte das in Abb. 17 dargestellte Ausblühungsbild, wobei sich 1 auf das

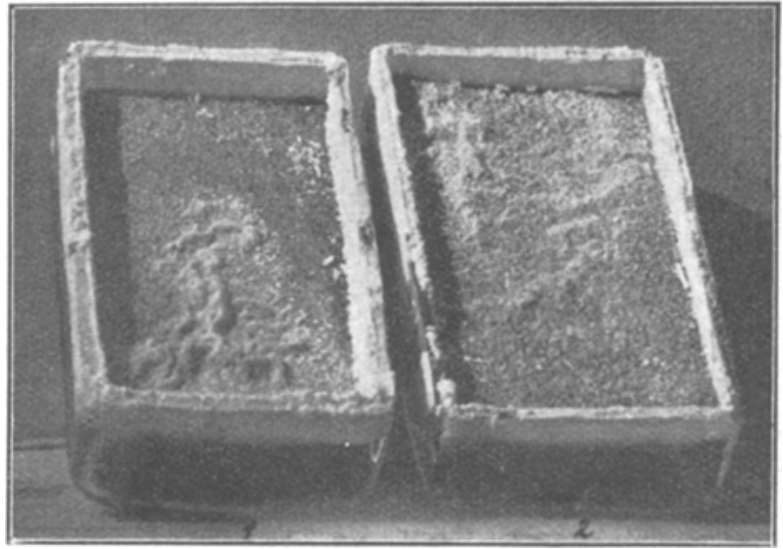

Abb. 17

Humusfreier Seesand (Sortiment I und II) mit 3 Gew.-Proz. $\mathrm{NaCl}$.

feinste Sortiment, dessen Teilchen kleiner als $0,25 \mathrm{~mm}, 2$ auf das nächstgröbere mit den bekannten Dimensionsgrenzen $0,25-0,5 \mathrm{~mm}$ bezieht. Das Gefä 11 war mit der unteren, das Gefäb 2 mit der oberen Kante während des Austrocknungsvorganges gegen ein geschlossenes Fenster hin aufgestellt gewesen. Die deutlich einseitige Anhäufung der Ausblühungen an diesen Kantenseiten des Sandkuchens weist auf die besonders der Verdunstung ausgesetzt gewesenen Stellen der Sandoberfläche hin. Wieder darf aber das Fehlen jeglicher Nadelbildung

39) Vgl. hierüber die Literatur nach $\mathrm{Ramann}$, Bodenkunde (Berlin 1911), 430. 
auf die Abwesenheit geeigneter organischer Kolloide zurückgeführt werden. Die Effloreszenzen bestanden vielmehr aus halb durchscheinenden bis mattgraten, unregelmäbig langgezogenen Rückenbildungen und erinnerten stark an die in Abb. 7 dargestellten Ausblühungen auf Kieselsäurehydrat, von welchen sie sich nur durch die wahrscheinlich infolge geringerer Feinheit der Kieselsäureteilchen bedingte gröbere Ausbildung unterschieden.

Welcher stofflichen Artung das organische Kolloid ist, das die nadelförmige Ausbildung der Effloreszenz auf den feinsten Sortimenten des humosen Quarzsandes verursacht, läft sich selbstredend zurzeit noch nicht in entferntesten angeben. Doch kann Verf feststellen, daß es sich im Gegensatz zu dem Kolloid des feinsten Dolomitsandes, der weiter oben besprochen wurde, um ein irreversibles Kolloid handeln tnuB. Denn löst man einige Salznädelchen in etlichen Tropfen destillierten Wassers im Uhrglas auf, so kristallisieren bei der Verdunstung tadellose $\mathrm{NaCl}$-Pyramidchen aus, während sich gleichzeitig an den Rändern der verdunsteten Wassertropłen ein unslòslicher Rückstand abscheidet, der sich beim Erhitzen schwärzt und $\mathrm{SiO}_{2}, \mathrm{Al}_{2} \mathrm{O}_{3}, \mathrm{Fe}_{2} \mathrm{O}_{3}, \mathrm{CaO}$ und $\mathrm{MgO}$ als Bestandteile qualitativ nachweisen labt. Genau dieselben Befunde erzielte Verf. mit nadelförmigen Ausblühungen aus Hochmoortorf, Niederungstorf und dem stark humosen feinsten Sortiment aus glazialem Sandboden, wie er als Bodenkrume in der westlichen und nördlichen Umgebung von München vorkommt. Daß hier ein anderes Kolloid als bei Dolomitsand vorliegt, erscheint auch insofern wahrscheinlich, als sich beim Dolomitsand weniger Rückstand der wässerigen Lösung der Ausblühung ergab, als zu. erwarten war, beim humosen Quarzsand ein Plus darüber. Der Flumus im Dolomitsand stellt einen absorptiv stark gesättigten, jener im humosen Quarzsand eiven absorptiv schwach gesättigten Komplex dar.

Der mögliche Einwand, daß einerseits die Ausbildung der Nadelform der $\mathrm{Na} \mathrm{Cl}$-Effloreszenz und die Bildung rein kristalliner, aber formloser Massen und feiner Pulver, andere seits die Entwicklung wohlausgebildeter, regelmäBiger Kristallfurmen des $\mathrm{NaCl}$ in der Ausbiühung überhaupt picht dirrch Vorhandensein oder Fehlen von Beimengungen zur NaCl-Lösung bedingt wird, sondern einfach eine Folge verschieden 3chneller Verdunstung sei, kann dadurch entkräftet werden, daß die verwendeten feinsten Materialsortimente infolge ihrer Herstellung durch gleichheitliehes Sieben alle dieselben Kondimensionsgrenzen, nämlich $<0,25 \mathrm{~mm}$ aufwiesen und die Verdunstung stets unter gleichen Bedingungen stattfand, dak auch die Unterschiede in spezifischer Wàme und Wàrmeleitungsvermögen nach der getroffenen Auswahl nur verschwindend gering sein konnten, mit anderen Worten, dab auch die Verdunstungsgröß in allen Fällen nur auBerordentlich wenig Unterschiede aufzuweisen vermochte. Vielmehr dürfen wir in den vorliegenden Ergebnissen einen netuen $\mathrm{Bew}$ e is für den EinfluB von Kolloiden auf die Fähigkeit 2 ur Kristallisation von Salzen und deren Formen erblicken.

Zum Schlusse sei noch betont, dab bei allen untersuchten Sanden das Gemisch sämtlicher Sortimente, also der unveränderte, durch Sieben nicht zerlegte Boden, bei Ausblühungsversuchen stets ein Verhalten zeigt, welches dem des feinsten Sortiments stark genähert, wenn auch diesem nicht vollkommen gleichheitlich geartet erscheint. Es soll auch nicht übergangen werden, daB sich Verf. dariuber klar ist, welchen entscheidenden Einflub neben der stofflichen Artung des Bodens auch die Menge des ihm zugesetzten Salzes auf die Entstehung der Ausblühung hat. Wiederholt wurde in vorliegender Abhandlung auch dieser Gesichtspunkt gestreift. Es wird für jeảen Boden und für jedes Salz einen "Schwellenwert" geben, nach dessen Erreichung überhaupt erst eine Ausblühung sich einstellen kann. So wurde vom Verf. gefunden, daB bei Torfsorten erst bei einem Gehalt an 12 Gew.-Proz. $\mathrm{Na} \mathrm{Cl}$ sich Effloreszenzen bemerkbar machen, der "Schwellenwert" lag für humosen Quarzsand bei $2-21 / 4$ Gew.-Proz. usw. Zunächst sei aber von dieser Seite der in Angriff genommenen Frage abgesehen.

Vielmehr beabsichtigt Verf. vorderhand, die begonnenen Versuche inter Verwendung anderer Böden und anderer Salze und zwar zunächst eines Salzes mit elektronegativem Ion fortzusetzen. Dabei werden sich Anhalte gewinnen lassen, welche die zur Erklärung der vorstehend aufgeführten Versuchsergebnisse niedergelegten Ausführungen entweder berichtigen und ergänzen oder bestätigen können. 